\title{
ANALYTIC FRAMEWORKS FOR ASSESSING DIALOGIC ARGUMENTATION IN ONLINE LEARNING ENVIRONMENTS
}

This is a post -print of an article submitted for consideration in the Educational Psychology Review (C) 2007 Springer Verlag.

Personal use of this manuscript is permitted. Permission from Springer Verlag must be obtained for any other commercial purpose.

This article may not exactly replicate the published version, due to editorial changes and/or formatting and corrections during the final stage of publication. Interested readers are advised to consult the published version which can be found at:

$\underline{\text { http://www.springerlink.com/content/t007257170766073/ }}$

doi: $\{10.1007 / \mathrm{s} 10648-007-9050-7\}$

Please refer this manuscript as:

Clark, D. B., Sampson, V., Weinberger, A., \& Erkens, G. (2007). Analytic frameworks for assessing dialogic argumentation in online learning environments. Educational Psychology Review, 19(3), 343-374. 


\title{
Analytic Frameworks for Assessing Dialogic Argumentation in Online Learning Environments
}

\begin{abstract}
Over the last decade, researchers have developed sophisticated online learning environments to support students engaging in argumentation. This review first considers the range of functionalities incorporated within these online environments. The review then presents five categories of analytic frameworks focusing on (1) formal argumentation structure, (2) normative quality, (3) nature and function of contributions within the dialog, (4) epistemic nature of reasoning, and (5) patterns and trajectories of participant interaction. Example analytic frameworks from each category are presented in detail rich enough to illustrate their nature and structure. This rich detail is intended to facilitate researchers' identification of possible frameworks to draw upon in developing or adopting analytic methods for their own work. Each framework is applied to a shared segment of student dialog to facilitate this illustration and comparison process. Synthetic discussions of each category consider the frameworks in light of the underlying theoretical perspectives on argumentation, pedagogical goals, and online environmental structures. Ultimately the review underscores the diversity of perspectives represented in this research, the importance of clearly specifying theoretical and environmental commitments throughout the process of developing or adopting an analytic framework, and the role of analytic frameworks in the future development of online learning environments for argumentation.
\end{abstract}

\section{Introduction}

Online learning environments that engage and support students in dialogic argumentation provide excellent opportunities for students to productively propose, support, evaluate, critique, and refine ideas. Over the last decade, a number of sophisticated environments have been developed to support students engaging in this type of knowledge-building discourse. Measuring the nature and quality of dialogic argumentation in these environments, however, has proven challenging. Thus, in order to facilitate research and development of these learning environments, this review highlights the foci, affordances, and constraints of several different analytic methods for assessing dialogic argumentation that are currently available to researchers. In addition to providing an overview of available methods, this review also synthesizes a picture of what the field considers important and desirable in terms of dialogic argumentation within online learning environments.

\section{Harnessing online learning environments to promote argumentation}

In order to provide a context for our discussion of analytic methods, we first outline the functionalities of online learning environments for dialogic argumentation. Online learning environments can provide a broad range of specific instructional functions to promote dialogic argumentation and to facilitate active learning beyond what can be achieved in traditional learning environments (Fabos \& Young, 1999; Fischer, 2001; Marttunen \& Laurinen, 2001; Pea, 
1994; Roschelle \& Pea, 1999; Schellens \& Valcke, 2006). Some of these functions involve standard online technologies, such as (1) structures that promote collaboration, (2) easily accessible and indexed knowledge bases, (3) asynchronous communication, and (4) enriched representations of focal subject matter. Other functions are not (yet) standard technology. These include state-of-the-art tools specifically designed to support dialogic argumentation in online learning environments, such as (5) dynamic visualization of students' arguments, (6) sociocognitive structuring, and (7) awareness heightening tools. It is important to note that not all online environments designed to foster dialogic argumentation incorporate all of these features. Rather, environments integrate subsets of these features (and potentially others) in order to support the designers' theoretical perspectives on argumentation and specific pedagogical goals. Structures that promote collaboration. Online learning environments can facilitate productive argumentation by structuring the nature of the environment so that it promotes and supports collaborative interactions between students (Kuhn, Shaw, \& Felton, 1997; Schwarz, Neuman, Gil, \& Ilya, 2001). In CSILE (Computer-Supported Intentional Learning Environment), for example, students access an online area in which they are encouraged to interact with each other in order to co-construct a shared understanding of a topic (Scardamalia \& Bereiter, 1994). Standard synchronous and asynchronous communication systems, such as Netmeeting or Allaire Forum, have also been used to promote collaboration by enabling communication between locally distant students (Veerman, 2003; Veerman, Andriessen, \& Kanselaar, 1999; Veerman \& Treasure-Jones, 1999). In addition to these types of communication interfaces, some online learning environments incorporate tools that enable students to co-create intellectual artifacts. For example, the CONNECT environment (Confrontation, Negotiation, and Construction of Text) enables students to co-create a text by using interfaces that structure the nature of the task and promote communication between the students (e.g., de Vries, Lund, \& Baker, 2002). Similarly, the TC3 (Text Composer, Computer-supported \& Collaborative) environment provides different source material for each student, chat functionality, and a shared text construction space (Erkens, Kanselaar, Prangsma, \& Jaspers, 2003). This type of structure has also been applied in face-to-face environments where groups of students share one computer or a set of personal workstations and a projection system (e.g., Koschmann, Kelson, Feltovich, \& Barrows, 1996).

Easily accessible and indexed knowledge bases. A second function for promoting productive argumentation involves providing students with the information they need in order to justify and evaluate ideas. Online environments can provide access to knowledge bases that contain information necessary to solve a problem or to understand a phenomenon under investigation. These knowledge bases can be built by students (as in the CSILE case), constructed by curriculum developers or teachers (e.g., WISE), or drawn from the greater online community in the World Wide Web. Accordingly, knowledge bases may range from glossaries embedded within specific online learning environments to the greater World Wide Web or specified sections thereof such as online libraries. With the help of search engines, students analyze background information within the knowledge bases for constructing their arguments or critiquing the arguments of others. Kolodner and colleagues (Kolodner et al., 1997), for example, built an indexed case library that students search for examples and facts as evidence for their arguments about a specific problem. To support students' examination of counterarguments to their own line of argumentation, the case library provides and indexes alternative solutions. Asynchronous communication. Many online learning environments incorporate asynchronous opportunities for online collaboration and discussion. Asynchronous communication facilitates 
task-oriented discussions and individual knowledge construction by allowing participants time to reflect, understand, and craft their contributions and responses (Schellens \& Valcke, 2006). This expanded time allows students to construct and (re-)evaluate textual arguments more carefully than in face-to-face environments (Joiner \& Jones, 2003; Marttunen \& Laurinen, 2001; Pea, 1994). Recent computer-mediated communication techniques, such as blogs and wikis, also allow the construction of non-sequential arguments in hypertext (Carter, 2003; Wolfe, 1995). The text-based nature of these asynchronous online environments (as opposed to speech-based) is believed to supplement the construction of complex and well conceived arguments. Enriched representations of focal subject matter. Enriched representations can provide significant information to students while imposing relatively little cognitive load (Fisher \& Larkin, 1986). Online learning environments can incorporate media-rich representations of the learning task, materials that enhance the authenticity of the learning task, and contextual anchors to facilitate applicable knowledge (Bransford, Brown, \& Cocking, 2000; Cognition and Technology Group at Vanderbilt, 1997). These environments can challenge students to identify the relevant problem information within complex problem cases and then create an appropriate solution strategy using these materials. Finally, students can collect evidence for their argumentation by interacting with rich representations. Visualizations and simulations may allow students to explore aspects of the subject matter for data that can be used to support a specific claim, for example, thereby potentially increasing the persuasiveness of their arguments (see Oestermeier \& Hesse, 2000).

Dynamic visualization of students' arguments. Whereas the first four categories of functionality involve standard software and technologies, online learning environments can also include several categories of specialized functionality for dialogic argumentation. The first of these categories involves tools that allow students to represent their own argumentation graphically. Tools such as these have been investigated with respect to how the exchange of a permanent external representation of the arguments (often in the form of a concept map) within a group of students may guide students to improve their dialogic argumentation (Fischer, Bruhn, Gräsel, \& Mandl, 2002; Kirschner, Buckingham Shum, \& Carr, 2003; Suthers \& Hundhausen, 2001). The DUNES system (Schwarz \& Glassner, in press), for example, supports students engaging in dialogic argumentation through their co-construction of a rich argumentation map in which shapes represent types of contributions (e.g., information, argument, comment, or question) and arrows between shapes show connections (with solid arrows signifying support and dashed arrows signifying opposition). Students indicate conviction with regard to a contribution by darkening the shade of an object. This rich map functionality significantly facilitates students' argumentation processes (Schwarz \& Glassner, in press). The diagramming functionality in the Virtual Collaborative Research Institute (Janssen, Erkens, Jaspers, \& Kanselaar, 2006), SenseMaker (Bell, 1997, 2004; Bell \& Linn, 2000; Linn, Clark, \& Slotta, 2003) and Belvedere (Cavalli-Sforza, Lesgold, \& Weiner, 1992; Suthers \& Hundhausen, 2001) are similar visualization tools that can help students coordinate evidence between alternative claims. While the primary design motivation for SenseMaker and Belvedere focuses on students' development of a rhetorical argument, SenseMaker and Belvedere can also facilitate productive dialogic argumentation and debate between students by helping students visualize respective arguments and relevant data.

Socio-cognitive structuring. The second category of specialized functionality involves sociocognitive structuring. Socio-cognitive structuring entails specifying, sequencing, and assigning roles and activities to students (Fischer, Kollar, Mandl, \& Haake, in press; Weinberger, 2003). 
Based on O'Donnell's (1999) scripted cooperation approach, computer-supported collaboration scripts have been developed to orchestrate socio-cognitive structuring. Stegmann, Weinberger, and Fischer (2006), for example, enact argumentative scripts through text prompts that guide students' interaction through specific argumentation sequences. Supports of this type focus on scaffolding students through a sequence of steps in the argumentation process to elevate the overall quality of the argumentative process. Other socio-cognitive structuring approaches focus specifically on grouping students with opposing perspectives. Jermann and Dillenbourg (2003), for example, designed the ArgueGraph script that identifies students' opinions through a questionnaire and then represents the students' stances in a graph. The software then matches pairs of opposing opinions with the largest distance on the graph into groups to construct and exchange arguments and counterarguments. Throughout this process, the software dynamically represents changes in the participants' positions on the graph. Similarly, Clark and Sampson (in press) developed the Personally-Seeded Discussion interface that organizes students with different perspectives on a topic into asynchronous discussion forums using their ideas as the initial seed comments.

Awareness heightening tools. A third category of specialized functionality involves awareness heightening tools that inform students about the quality of their dialogic argumentation. These tools thereby provide information about situational affordances to students in dialogic argumentation (Hesse, in press). Based on the feedback from these tools, participants can modify and improve their argumentation. Whereas socio-cognitive structuring organizes an ideal sequence of arguments, the awareness heightening approach relies on enhancing students' understanding of their participation to enhance their dialogic argumentation. Design of awareness tools focuses on the types of information that can and should be mirrored back to students (Jermann, Soller, \& Muehlenbrock, 2001). Awareness tools can heighten awareness of participation in terms of the number of words students contribute, the number of comments made, or the connections established in terms of who has spoken to whom (e.g., Erkens \& Janssen, 2006; Dillenbourg, 2002). Researchers have also developed awareness tools that utilize sophisticated computer-based text analysis technology to provide feedback based on automated analysis of students' argumentation (Dönmez, Rosé, Stegmann, Weinberger, \& Fischer, 2005; Jermann, Soller, \& Muehlenbrock, 2001).

Summary of online learning environment supports and affordances for dialogic argumentation. As outlined above, researchers have developed tools providing several categories of functionality to foster dialogic argumentation in online learning environments (Marttunen, 1992, 1997; Marttunen \& Laurinen, 2001). These types of cognitive tools can shape how people think about accomplishing a task because they have a strong influence on the ways people attempt to accomplish a task (Hutchins, 1995; Norman, 1990). This is particularly true when tasks require individuals to gather, organize, communicate, or make sense of information (Reiser, 2002). According to Norman (1987), when cognitive tools are used to represent and manipulate information, these tools become the vehicle through which a person interacts with the subject matter. Thus, the nature of the task emerges through the interactions of people, subject matter, and tools.

Rather than focusing on a single category of functionality, most online learning environments designed to support dialogic argumentation integrate several of these tools or incorporate tools that serve multiple functions. For example, ArguGraph (1) provides a dynamic visualization of students' argumentation, (2) guides students through a number of individual and collaborative phases, (3) engages socio-cognitive structuring, and (4) makes students aware of their opinions 
about the theories in question. Similarly, the DUNES system (1) provides easily accessible databases, (2) provides a dynamic visualization of students' argumentation, (3) guides students through a number of individual and collaborative phases, (4) engages asynchronous and synchronous functionalities, and (5) makes students aware of their opinions about the theories in question. Thus, in practice, these online learning environments engage complex interrelationships of these functionalities depending on the designers' theoretical perspectives on argumentation and pedagogical goals. This is important for the current discussion because researchers' diverse theoretical perspectives on argumentation, pedagogical goals, and environment structures give rise to similarly diverse goals and requirements for the analytic methods chosen to measure the nature of argumentation occurring within these environments.

\section{Assessing argumentation quality in online learning environments}

Given the complexity of issues that drive the development of the online environments discussed above, we can know turn our attention to the complexities and challenges that face researchers when they attempt to measure how students engage in argumentation within these environments. To date, researchers have developed a broad range of methods to assess the nature or quality of dialogic argumentation within online learning environments. These methods reflect specific perspectives on argumentation, pedagogical goals, and environment structure characteristics. The goal of this manuscript involves analyzing the foci, affordances, and constraints of a broad range of available analytic methods that, when taken together, can provide researchers with valuable insights into the assessment of student argumentation.

\section{Argumentation Example for Comparison}

In order to facilitate the comparison of these analytic methods, this review focuses on a short segment of student argumentation. This example is taken from earlier work that focused on supporting and promoting argumentation in an online learning environment. The students in the example are arguing within a customized asynchronous threaded discussion forum about their interpretations of data they have collected in earlier parts of the project (Clark and Sampson, in press). The students in this example are arguing about the temperature of different objects in the room. They have completed a series of experiments using computer probes and simulations. At the heart of their argument is the scientific principle of thermal equilibrium.

Fran: I think objects in the same room remain different temperatures because some objects are good conductors and some are bad. This determines how much heat energy is allowed in and out of the object.

Amy: I disagree; I think all objects in the same room are the same temperature. Conductivity only determines how quickly an object will reach room temperature.

Fran: No, good conductors let in more heat energy than poor conductors, so objects that let in more heat will get hotter. For example, when I put a piece of metal and a piece of plastic in hot water the metal was a higher temperature after 30 seconds.

Amy: I guess you're right. Maybe objects are different temperatures. 
In order to facilitate later discussion about this example, we first clarify aspects of the scientific subject matter involved. From a normative scientific perspective, all objects in the room should become the same temperature over time unless they produce their own heat (e.g., a lighted light bulb or a living person). This happens because of a net heat transfer between higher temperature objects and lower temperature objects until all of the objects are the same temperature. This includes the air. Students, however, are very aware from their daily experiences that some materials often feel hotter or colder than others in the room. Metal objects, for example, generally feel colder than wooden objects. From a normative scientific perspective, the metal objects feel colder because they have a greater thermal conductivity, which essentially means that heat transfers more quickly through them. As a result, heat transfers more quickly out of a person's hand (which is a higher temperature) into a metal chair than into a wooden table of the same temperature. Hence, even though the metal chair and wooden table are the same temperature as each other and the rest of the room, the metal chair feels colder because of its higher thermal conductivity.

In the example, "Fran" is convinced that objects remain different temperatures. She explains that conductivity determines how much total heat energy is allowed in and out of the object (which is not correct). "Amy" disagrees and says that conductivity only affects the rate of heat transfer until the equilibrium temperature (the room temperature in this example) is reached (which is essentially correct for the purposes of this discussion). Fran then reiterates her point and supports this point with data from an experiment they did. Amy then changes her position and agrees with Fran.

It is important to note that the sample argument outlined above is purposefully very short in order to allow us to compare several analytic methods within a single manuscript. Many of the analytic methods discussed in this manuscript were developed to analyze much more detailed arguments and thus will not be shown to their full potential in analyzing such a short sample. We attempt to take the brevity of the example into account in our discussion of each framework. A second important caveat is that this review focuses on dialogic argumentation rather than what the literature often refers to as rhetorical argumentation. As a result, this manuscript does not cover the diverse array of analytic frameworks for analyzing rhetorical arguments (by authors such as Greg Kelly, William Sandoval, and others). Another manuscript is under development to address these analytic methods for rhetorical argumentation (Sampson \& Clark, 2006; Sampson \& Clark, in preparation).

\section{Selection Criteria for the Review}

How should researchers of online learning environments interpret our student example in terms of argumentation quality? In answering this question, researchers must choose valid and reliable analytic methods that are compatible with their theoretical perspectives on argumentation, pedagogical goals, and the structure of their online learning environment. The analytic methods discussed in this review were chosen to represent a range of promising approaches for analyzing dialogic argumentation in online learning environments. The selection process focused on each method's capabilities for assessing dialogic argumentation within online environments independent of whether or not the method had been originally developed for application in online or offline environments. We categorize our discussion of these methods in terms of each method's analytic focus. The categories of analytic focus include (1) formal argumentation 
structure, (2) normative quality, (3) nature and function of contributions within the dialog, (4) epistemic nature of reasoning, and (5) patterns and trajectories of participant interaction.

\section{Formal Argumentation Structure}

Formal argumentation structure provides a common and reasonable focus for analytic methods as well as pedagogical approaches that are designed to foster argumentation. Toulmin's The Uses of Argument (1958) is probably the most heavily cited method for the assessment of argumentation in general and certainly the most heavily cited in terms of formal argumentation structure (within technology-enhanced learning environments or without). We therefore begin with Toulmin even though his framework focuses neither specifically on dialogic argumentation nor on technologybased environments. We then discuss Erduran, Simon and Osborne's (2004; Osborne, Erduran, and Simon, 2004) adaptation of this approach to the analysis of students' dialogic argumentation.

\section{Toulmin: A Core Foundation for Argumentation Structure}

Toulmin's framework suggests that the components of an argument have different functions that can be classified into one of six categories: Claims (assertions about what exists or what values people hold), Data (statements that are used as evidence to support the claim), Warrants (statements that explain the relationship of the data to the claim), Qualifiers (special conditions under which the claim holds true), Backings (underlying assumptions), and Rebuttals (statements that contradict either the data, warrants, or backings of an argument). Toulmin describes the process of argumentation primarily as a process of using data, warrants and backings to convince others of the validity of a specific claim (Figure 1). From this perspective, the strength of an argument is based on the presence or absence of these different structural components. Stronger arguments contain more of these different components than weaker arguments. Toulmin indicates (1) that context determines which components are necessary in a given situation and (2) that field-dependent criteria determine the quality of each component. Analyses of argumentation using Toulmin's argument model have primarily examined how students provide data and warrants for claims, when they do, and on what basis.

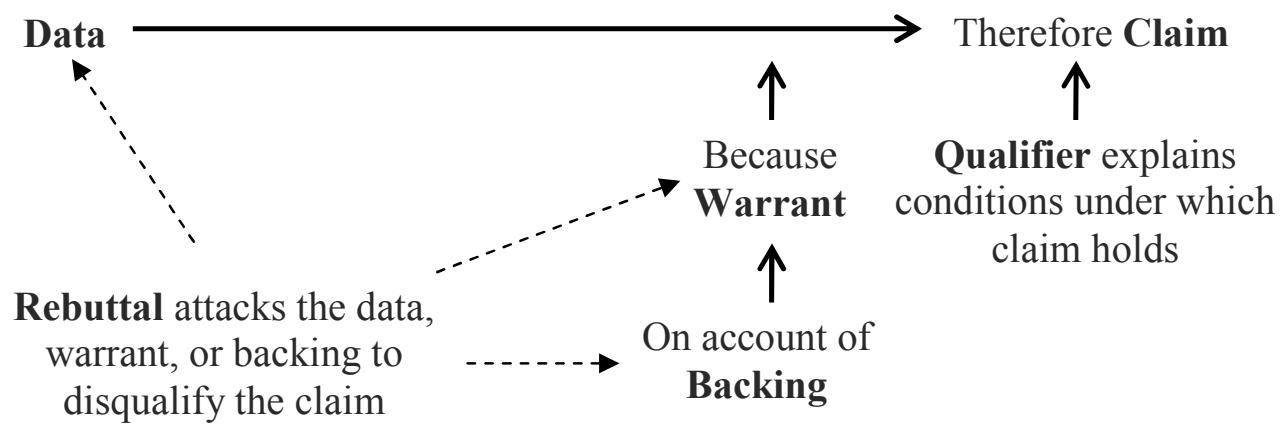

Figure 1: Toulmin's model of an argument

The application of Toulmin's framework to our student example therefore focuses primarily on the inclusion of warrants, data, and backings to support claims. Toulmin does not provide 
specific criteria for categorizing ongoing dialog or content quality. Instead, dialogic argumentation can be analyzed with Toulmin's argument components by interpreting components in the context of the components to which they refer. A backing, for example, can be interpreted as a claim for yet another argument. Similarly, a rebuttal can be interpreted as a counter-claim (Voss \& van Dyke, 2001). Based on the categories provided by Toulmin, the students in our example provide warrants and data for their claims (as labeled in Table 1 below). The students therefore seem to be engaging in reasonably high-quality argumentation.

Table 1: Application of Toulmin's (1958) framework to example argumentation

Fran: I think objects in the same room remain different temperatures [CLAIM] because some objects are good conductors and some are bad [DATA]. This determines how much heat energy is allowed in and out of the object [WARRANT].

Amy: I disagree; I think all objects in the same room are the same temperature [COUNTERCLAIM]. Conductivity only determines how quickly an object will reach room temperature [WARRANT].

Fran: No, good conductors let in more heat energy than poor conductors, so objects that let in more heat will get hotter [REBUTTAL]. For example, when I put a piece of metal and a piece of plastic in hot water the metal was a higher temperature after 30 seconds [DATA].

Amy: I guess you're right. Maybe objects are different temperatures.

\section{Erduran, Simon, and Osborne: Adapting Toulmin to Dialogic Argumentation in the Classroom.}

Erduran, Simon, and Osborne (2004, Osborne, Erduran, and Simon, 2004) apply Toulmin's model as a way to identify the salient features of argumentation during small group and whole class discourse. Erduran, Simon, and Osborne characterize the argumentative operations that occur during dialog that is oppositional in nature. These argumentative operations include: (a) opposing a claim, (b) elaborating on a claim, (c) reinforcing a claim with additional data and/or warrants, (d) advancing claims, and (e) adding qualifications.

After identifying the argumentative operations, the quality of the argumentation that takes place during these episodes is assessed using the hierarchy outlined in Table 2. This hierarchy is based on two major assumptions about what counts as quality as defined by Erduran, Simon, and Osborne. First, high quality arguments must contain grounds (i.e., data, warrants, or backing) to substantiate a claim because "developing rational thought is reliant on the ability to justify and defend one's beliefs" (Erduran et al., 2004, p. 926) and argumentation that does not contain any justification "is essentially a discursive interaction incapable of any resolution" (Erduran et al., 2004, p. 926). Second, argumentation that include rebuttals is "of better quality than those without, because oppositional episodes without rebuttals have the potential to continue forever 
with no change of mind or evaluation of the quality of the substance of an argument" (Erduran et al., 2004, p. 927).

Table 2: Dialogic argumentation hierarchy developed by Erduran, Simon, and Osborne (2004)

\begin{tabular}{ll}
\hline Quality & Characteristics of Argumentation \\
\hline Level 5 & Extended arguments with more than one rebuttal. \\
Level 4 & $\begin{array}{l}\text { Arguments with a claim with a clearly identifiable rebuttal. Such an argument } \\
\text { may have several claims and counterclaims as well, but this is not necessary. }\end{array}$ \\
Level 3 & $\begin{array}{l}\text { Arguments with a series of claims or counterclaims with data, warrants, or } \\
\text { backings with the occasional weak rebuttal. }\end{array}$ \\
Level 2 & $\begin{array}{l}\text { Arguments consisting of claims with data, warrants, or backings, but do not } \\
\text { contain any rebuttals. } \\
\text { Arguments that are a simple claim versus a counterclaim or a claim versus } \\
\text { claim. }\end{array}$ \\
\hline
\end{tabular}

Erduran, Simon, and Osborne's analytic framework assesses the individual elements of our student example quite similarly to Toulmin's approach (Table 1). One difference involves collapsing the data, warrant, and backing category into a single "grounds" category due to the practical challenges of distinguishing between data, warrants, and backings in student work. Overall, the student example would be considered a Level 4 argument according to Erduran, Simon, and Osborne's hierarchy of dialogic argumentation outlined in Table 2 because the argumentation includes a clearly identifiable rebuttal against the grounds of an opposing claim. The example would therefore represent fairly high quality argumentation from the perspective of this framework.

\section{Formal Argumentation Structure: Affordances, Constraints, and other Considerations}

Toulmin's framework provides solid basic affordances that have led many researchers to use this framework for their analytic methods (or at least as a foundation). Toulmin's framework provides a way to examine argument structure regardless of discipline or domain. Argument quality is based on the presence or absence of the various components. While this framework seems very objective, however, differentiating between data, warrants, and backings often proves difficult in practice (e.g., Crawford et al., 2000; Eichinger, Anderson, Palincsar, \& David, 1991; Forman, Larreamendy-Joerns, Stein, \& Brown, 1998; Jimenez-Aleixandre et al., 2000). Therefore, reducing these difficulties is a significant methodological challenge for any researcher who wishes to use Toulmin's argument model to study dialogic argumentation.

Another constraint of Toulmin's argument framework is the fact that it provides little information about field-dependent features. According to Toulmin's framework, claims, warrants, data, and backings are field-invariant features of an argument that can be used to study the structure of an argument regardless of context. However, what counts as an appropriate claim, warrant, backing, or datum are field-dependent features of an argument (Toulmin, 1958). As a result, much work utilizing Toulmin-based frameworks focuses only on field-invariant structural issues rather than field-dependent assessments of quality or issues related to content. 
Regardless of these potential constraints, however, Toulmin's framework remains extremely noteworthy by virtue of the vast preponderance of researchers who have based their analytic frameworks in Toulmin's work.

Erduran, Simon, and Osborne's framework builds on Toulmin's framework by allowing us to focus on the overarching nature of the argumentation rather than focusing only on the individual components. Furthermore, application of Toulmin's general framework is greatly facilitated by Erduran, Simon, and Osborne's creation of a single grounds category to represent data, warrants, and backings. However, by adopting the Toulmin frameworks focus on field-invariant structural features of argumentation, this framework precludes learning how (or if) students' conceptual ideas about the subject matter influence how they coordinate theory with evidence as they construct an argument in support of a particular viewpoint.

Overall, these Toulmin-inspired approaches are well-suited for online-environments where the content of students' argumentation will cover multiple topics because of the field independent nature of the approach. Essentially, the field independence becomes an affordance rather than a constraint. Secondly, this type of framework is primarily useful for analyzing environments involving ongoing stream of dialog, whether synchronous or asynchronous, rather than the production of an in-depth product, such as concept map or several paragraphs of text. These frameworks work better for streaming dialog because this type of framework tends to rely on frequency counts to determine quality rather than more detailed analysis. Thirdly, frameworks such as these should obviously be applied to environments when the pedagogical goal focuses on argumentation structure. Osborne, Erduran, and Simon (2004), for example, make that specific pedagogical choice because they believe that it is a content-independent transportable model that teachers and students will find accessible as an achievable initial goal in improving their understanding of argumentation. This is an important example of matching theoretical perspectives on argumentation, pedagogical goals, and environmental structure with analytic methods.

\section{Normative Quality}

Another potential focus of pedagogy and analysis revolves around the normative quality represented in students' argumentation. This type of focus is often integrated with additional analytic foci. Clark and Sampson's (2006) analytic framework, for example, expands on Erduran, Simon, and Osborne's structural framework to incorporate measurement of conceptual quality and grounds quality. Kuhn and Udell (2003) compare the frequencies of different types of epistemic contributions that students make with the normative quality of students' arguments before and after the dialog. Hogan, Nastasi, and Pressley's (2000) analysis of reasoning complexity is also a good example of this category of analytic focus (although Hogan, Nastasi, and Pressley's framework is actually discussed below in Patterns and Trajectories of Participant Interaction rather than in this category due to their insightful approaches for analyzing patterns of interaction).

\section{Clark and Sampson: Integrating Content Quality and Grounds Quality}

Clark and Sampson's framework $(2005,2006)$ focuses on analyzing the relationships between the structural quality of discourse episodes and the nature, conceptual quality, and grounds quality of constituent student contributions. Clark and Sampson developed the framework for research on an online argumentation environment with a customized asynchronous threaded 
discussion forum. Earlier research found that students frequently rely on idiosyncratic explanations and qualifiers to distort or trivialize evidence to match their claims (Clark and Sampson, 2005). These findings supported Chinn and Brewer's (1993) perspectives on students' treatment of anomalous data and Kuhn, Garcia-Mila, Zohar and Anderson's (1995) research suggesting that students' theoretical beliefs shape evidence.

Clark and Sampson's analytic framework incorporates two flow charts built of binary decisions to code comments in online discussions for conceptual quality and grounds quality. The fourpoint scale for conceptual quality operates on concept facet lists specific to the domain. The ordinal scale includes codes for (1) non-normative content, (2) transitional content involving a mix of normative and non-normative ideas, (3) primarily normative content, and (4) normative content with nuanced connections between multiple normative ideas. The ordinal scale for grounds quality includes codes for (1) no grounds provided, (2) explanation only with no evidence, (3) explanation with evidence, and (4) coordination of multiple pieces of evidence. The framework does not provide nuanced detail in terms of the epistemic nature of students' reasoning (see Epistemic Nature of Reasoning below) but codes grounds quality with high reliability due to the streamlined scheme. The incorporation of coding flowcharts enhances this reliability.

Structurally, Clark and Sampson code individual comments in a manner similar to Erduran, Simon, and Osborne (2004), but Clark and Sampson also focus on the nature and function of non-argumentative contributions (see further discussion in Nature and Function of

Contributions Within the Dialog below). Clark and Sampson code the overarching quality of argumentation based on the constituent comments (Table 3) in manner similar to Erduran, Simon, and Osborne's hierarchy outlined in Table 2. In the hierarchy used by Clark and Sampson, however, "rebuttals" directed against the thesis of a comment are also considered important indicators of quality argumentation. In other words, a rebuttal against the thesis of a comment and a rebuttal against the grounds of a comment (which is the definition applied by Toulmin and Erduran, Simon, and Osborne) both represent epistemically valuable moves. This provides another example of how theoretical perspectives on argumentation, pedagogical goals, and the field-dependent features of argumentation influence and modify the development of analytic schemes. After episode quality has been established using Table 3, analysis using this framework then investigates the relationships between comment type, episode quality, comment conceptual quality, and grounds quality for the argumentation.

Table 3: Dialogic argumentation hierarchy used by Clark and Sampson (2006)

\section{Quality Characteristics of Argumentation}

Level 5 Argumentation involving multiple rebuttals and at least one rebuttal that challenges the grounds used to support a claim

Argumentation involving multiple rebuttals that challenge the thesis of a claim

Level 3 Argumentation involving claims or counter-claims with grounds but only a single rebuttal that challenges the thesis of a claim

Level 2 Argumentation involving claims or counter-claims with grounds but no rebuttals

Level 1 Argumentation involving a simple claim versus counter-claim with no grounds or rebuttals 
From the perspective of Clark and Sampson's framework, our student example (Table 4) represents higher quality argumentation in terms of structure than would be assessed by Erduran, Simon, Osborne (Level 5 according to Clark and Sampson in Table 3 as compared to Level 4 according to Erduran, Simon, and Osborne in Table 2) because it involves a distinct rebuttal against grounds as well as a rebuttal against thesis. In terms of normative quality, however, the argumentation is not as strong. Only one of the comments consists of nuanced normative content. Moreover, this episode illustrates how students can distort evidence to match claims. In this example, Fran convinces Amy to abandon her normative idea that objects sitting in the same room are in thermal equilibrium by providing inappropriate evidence in support of a nonnormative idea. Grounds use is also erratic.

Table 4: Application of Clark and Sampson's (2005) framework to example argumentation

Fran: I think objects in the same room remain different temperatures because some objects are good conductors and some are bad. This determines how much heat energy is allowed in and out of the object. [MOVE: CLAIM, GROUNDS: NONE, CONCEPTUAL QUALITY: NON-NORMATIVE]

Amy: I disagree; I think all objects in the same room are the same temperature. Conductivity only determines how quickly an object will reach room temperature. [MOVE: REBUTTAL AGAINST THESIS, GROUNDS: EXPLANATION, CONCEPTUAL QUALITY: NUANCED]

Fran: No, good conductors let in more heat energy than poor conductors, so objects that let in more heat will get hotter. For example, when I put a piece of metal and a piece of plastic in hot water the metal was a higher temperature after 30 seconds [MOVE: REBUTTAL AGAINST GROUNDS, GROUNDS: EVIDENCE, CONCEPTUAL QUALITY: NON-NORMATIVE]

Amy: I guess you're right. Maybe objects are different temperatures. [MOVE: CHANGE OF CLAIM, GROUNDS: NONE, CONCEPTUAL QUALITY: NON-NORMATIVE]

\section{Kuhn and Udell (2003)}

Kuhn and Udell's (2003) framework focuses on measuring development in students' argumentation skills over time. They integrate analyses of content normativity and epistemic/structural nature within their framework. The content component is domain-specific, involving specified hierarchical sets of arguments for (pro) and against (con) the topic being debated (which is capitol punishment in their study). The lowest level comprises Nonjustificatory Arguments, which have little or no argumentative force. The middle tier comprises Nonfunctional Arguments, which focus on tangential aspects of the problem rather than core issues. At the highest level, Functional Arguments address core aspects of the problem. 
The possible arguments in each tier are explicitly listed in order to compare content before and after instruction. The goal involves measuring changes in the sophistication of students' arguments and their understanding of the topic. This type of approach focuses on the logical coherence and relevance of the arguments generated by students as a way to measure normativity rather than the conceptual quality of the ideas proposed by students. This type of focus is especially well-suited for online environments where students' are encouraged to debate and discuss issues without clear "right" or "wrong" answers (such as capital punishment). A rubric of discourse codes (originally developed in Felton \& Kuhn, 2001) analyzes the nature of students' discourse as they propose, support, evaluate, and refine their ideas. This component of Kuhn and Udell's analytic method is actually exemplary of the third category of analytic foci (see Nature and Functions of Contributions Within the Dialog). Codes for twenty-five distinct discourse moves are included. These codes are applied to each "utterance" as defined by the moment someone starts speaking until their speaking turn ends. Three codes focus on challenges, which Kuhn and Udell consider as representative of argumentation: Counter- $A$ (counterargument with partner's utterance accompanied by an alternate argument), Counter-C (counterargument accompanied by a critique), and Disagree (disagreement without elaboration). Two exposition codes are considered as markers of non-argumentative discourse: Add (extension of previous statement), Clarify (clarification of speaker's argument in response to preceding utterance). Kuhn and Udell expect increased frequency of the challenge codes and decreased frequency of the exposition codes if students are increasing in the sophistication of their argumentation.

In addition to these five core argumentation marker codes, eight codes demark requests: Agree-? (do partners agree with the preceding claim), Case-? (what is their position on a specific case), Clarify-? (request for clarification), Justify-? (how they would justify a statement), Meta-? (question regarding the dialog itself), Position-? (what is their overall position on an issue), Question-? (what the answer is to a general question), and Respond-? (request for response to previous statement). Finally, the last fourteen codes mark other non-request discourse moves: Advance, Agree, Coopt, Aside, Dismiss, Interpret, Null, Refuse, Substantiate, Continue, and Unconnected. These additional codes are used to measure students' discourse habits in terms of the nature and function of contributions within the dialog.

Table 5. Application of Kuhn and Udell (2003) framework to argumentation example

$\begin{array}{ll}\text { Comment } & \text { Argumentation } \\ & \text { Operation }\end{array}$

Fran: I think objects in the same room remain different temperatures because some objects are good conductors and some are bad. This determines how much heat energy is allowed in and out of the object.

Amy: I disagree; I think all objects in the same room are the same Counter-C temperature. Conductivity only determines how quickly an object will reach room temperature. 
Fran: No, good conductors let in more heat energy than poor conductors, so objects that let in more heat will get hotter. For example, when I put a piece of metal and a piece of plastic in hot water the metal was a higher temperature after 30 seconds.

Counter-A

Functional

Argument

Amy: I guess you're right. Maybe objects are different temperatures.

Agree

From the perspective of Kuhn and Udell's framework, we would view the example as exceedingly short but representing quality argumentation (Table 5). The arguments presented by Fran and Amy are functional in terms of normativity, which indicates that these students address key aspects of the problem. Moreover, the discourse moves used by the students in this example heavily emphasize argumentative moves (e.g., challenging the ideas of others) rather than exposition (e.g., proposing or clarifying one's own ideas).

\section{Normative Quality of Content: Affordances, Constraints, and other Considerations}

In terms of affordances, an analysis of the normative quality of content allows the investigation of potentially important pedagogical issues regarding the relationship between argumentation and learning. For example, when the pedagogical goal of an online environment is to help students learn how to engage in argumentation (e.g., proposing, justifying, and challenging ideas), the analytic framework can focus on the structure of students' contributions to the discussion and still be sufficient. However, if the goal of the online environment is to provide an opportunity for students to learn from argumentation (e.g., develop a more in-depth understanding of the content that is being discussed), the analytic framework must also be able to examine the normative quality of students' ideas in order to assess the overall effectiveness of the environment.

In choosing an analytic framework, researchers must determine the importance of the relationship between the normativity of a comment and the relative time of its contribution. Nonnormative content at the onset of dialog followed by increasing normativity by the conclusion of the dialog might represent something entirely different than the reverse trajectory. Kuhn and Udell address the temporal issue by measuring the normativity of students' arguments before and after the dialog, for example, but do not examine the trajectories within the dialog itself (as discussed in Patterns and Trajectories of Participant Interaction below).

A focus on normativity of contributions or products fits well with environments that include easily accessible and indexed knowledge bases and enriched representations of focal subject matter (as discussed in the introduction) because these types of functionalities are often integrated into online environments designed to help students achieve specific content learning goals that are associated with the databases and enriched representations. In addition, environments that integrate asynchronous communication and awareness heightening tools can also benefit from this type of focus. By examining the content of student ideas and how students interact with each other, researchers can better support students as they attempt to negotiate meaning or validate ideas in online environments. One challenge, however, is that rubrics with a focus on normativity become very topic-specific and thus require significant modification for application across contexts. 


\section{Nature and Function of Contributions Within the Dialog}

Another category of analytic focus revolves around the nature of participants' contributions. Whereas approaches emphasizing formal argumentation structure focus specifically on the components of an argument, this type of framework focuses on the types of dialog in which students engage as well as the proportion of conceptually and argumentatively productive dialog. Kuhn and Udell (2003) and Clark and Sampson $(2005,2006)$ include analysis of the nature and function of contributions, as discussed in the preceding section, but the analytic frameworks of de Vries, Lund, and Baker's (2002) and Baker, Andriessen, Lund, van Amelsvoort, and Quignard (submitted) focus specifically on the analysis of the nature and function of students' contributions.

\section{de Vries, Lund, and Baker (2002)}

De Vries, Lund, and Baker (2002) examine ways to promote epistemic dialogue in online learning environments. As defined by deVries, Lund, and Baker, epistemic dialog (1) takes place in a collaborative problem-solving situation, (2) can be characterized as argumentation or explanation, and (3) concerns the knowledge and concepts underlying the problem-solving rather than the execution of problem-solving actions. To foster this type of discourse between students, deVries, Lund, and Baker integrate structures that promote collaboration, asynchronous communication, dynamic visualizations, socio-cognitive structuring, and awareness heightening tools into the CONNECT environment. In this environment, students work together in order to produce a piece of text that explains a puzzling phenomenon through a process of collaboration and negotiation.

Figure 2 outlines the categories they use to code this type of discourse. This scheme is typically applied at the phrase level of the discourse. Coders first determine the major discourse category in which the phrase occurred. The coders then assign a sub-type to each of the phrases based on the major category. Analysis involves qualitative and quantitative comparisons of the discourse in each category and subcategory across the phases of the project.

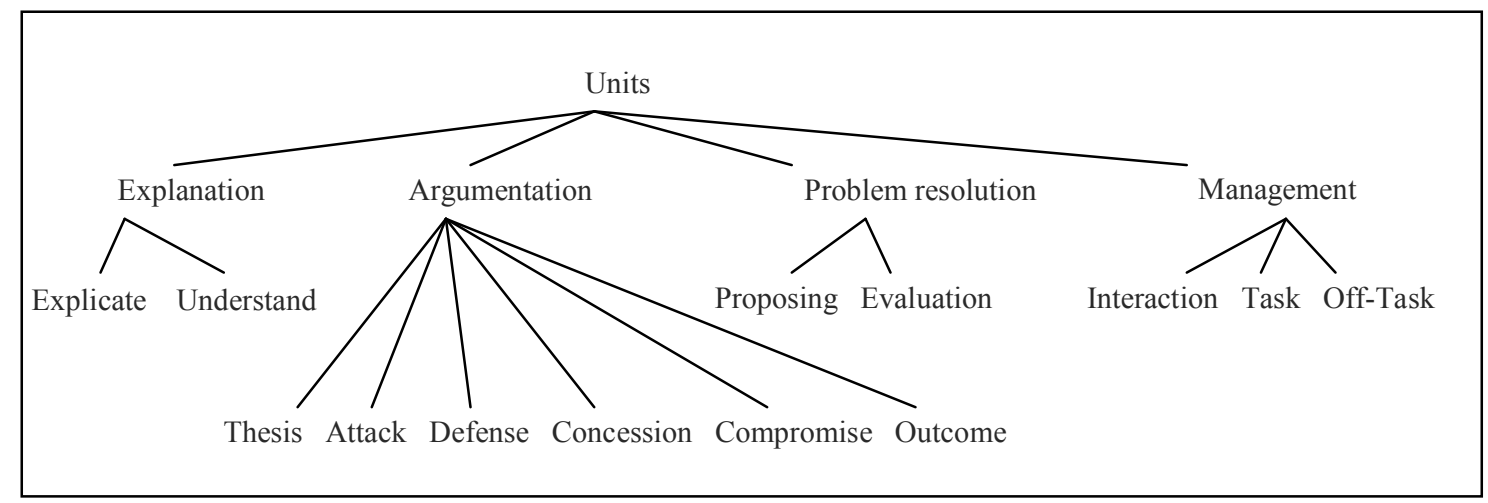

Figure 2. de Vries, Lund, and Baker's hierarchy of epistemic codes

Table 6 applies de Vries, Lund, and Baker's (2002) framework to our student example. From the perspective of this framework, the example represents desirable epistemic discourse because all four contributions to the discussion can be characterized as either explanation or argumentation. As previously mentioned, de Vries, Lund, and Baker suggest that explanation and argumentation 
are "potentially powerful mechanisms by which students can collaboratively construct new meaning" (2002, p.64).

Table 6. Application of de Vries, Lund, and Baker's (2002) framework to example argumentation

Fran: I think objects in the same room remain different temperatures because some objects are good conductors and some are bad [EXPLANATION-EXPLICATE]. This determines how much heat energy is allowed in and out of the object [EXPLANATION-EXPLICATE].

Amy: I disagree; I think all objects in the same room are the same temperature [ARGUMENTATION-THESIS]. Conductivity only determines how quickly an object will reach room temperature [ARGUMENTATION-ATTACK].

Fran: No, good conductors let in more heat energy than poor conductors, so objects that let in more heat will get hotter [ARGUMENTATION-DEFENSE]. For example, when I put a piece of metal and a piece of plastic in hot water the metal was a higher temperature after 30 seconds [ARGUMENTATION-DEFENSE].

Amy: I guess you're right. Maybe objects are different temperatures [ARGUMENTATIONCONCESSION].

The framework is especially well suited for the analysis of student argumentation in environments that incorporate asynchronous communication, socio-cognitive structuring tools, and awareness heightening tools. For example, an awareness heightening tool that is based on this type of framework could help students view the kinds of contributions they are making (e.g., procedural, off-task, or explanation) and if they are making too many inappropriate contributions (e.g., off-task). Students might learn to engage more productively through this formative feedback.

\section{Janssen, Erkens, Jaspers, \& Kanselaar (2006)}

Janssen, Erkens, Jaspers, \& Kanselaar (2006) automatic coding framework focuses on argumentative dialogue acts. The framework first identifies the communicative function of each utterance typed by the students during their online collaboration and communication (Erkens, Jaspers, Prangsma, \& Kanselaar, 2005). The five main communicative functions include: argumentative (indicating a line of argumentation or reasoning), responsive (e.g., confirmations, denials, and answers), informative (transfer of information), elicitative (questions or proposals requiring a response), and imperative (commands). The framework specifies twenty-nine different dialogue acts within these five main functions. Seven of the twenty-nine focus on argumentative dialog (Table 7). 
Table 7. Argumentative dialogue acts within Janssen, Erkens, Jaspers, and Kanselaar's framework (2006)

\begin{tabular}{|l|l|}
\hline Argumentative dialogue act & Example \\
\hline Argument-Reason (ArgRsn) & "because we have to write an advice on the guilt or \\
innocence of the old woman"
\end{tabular}

To automatically code a protocol and identify which dialogue acts are used during collaboration, the Multiple Episode Protocol Analysis (MEPA) computer program is used (Erkens, 2005). A production rule system automatically categorizes utterances into dialogue acts. A set of if-then rules uses pattern matching to look for typical words, phrases, and punctuation that serve as discourse markers signaling the communicative function of a sentence in conversation in natural language (Schiffrin, 1987). For example, "because" at the beginning of an utterance usually indicates a reason. The production rule system segments utterances in single messages ( 300 rules) and larger dialogue act s (1,300 rules). The computer-driven nature of the MEPA software obviously results in very high reliability thus making this system ideal for comparing interventions in online learning environments. The automated nature is also obviously attractive for research involving large volumes of data.

Based on these codings, MEPA calculates frequencies of sequences of argumentation consisting of two, three, four, or five arguments. These findings are then compared to group performance in terms of the shared texts constructed by each group. Shared texts are scored in terms of use of sources, content and argumentation, and text construction and language. Using this combined approach, Janssen, Erkens, Jaspers, and Kanselaar's framework allows analysis of various interventions, such as their awareness heightening tools, on both discourse and artifact quality. Janssen, Erkens, Jaspers, and Kanselaar's framework and automated coding system are thus intended for much longer interactions including artifact production, but from the perspective of the framework our student example represents an extend sequence of argumentation and is therefore of high quality (Table 8). 
Table 8. Argumentative dialogue acts within Janssen, Erkens, Jaspers, and Kanselaar's framework (2006)

Fran: I think objects in the same room remain different temperatures because some objects are good conductors and some are bad [ARGUMENT-REASON]. This determines how much heat energy is allowed in and out of the object. [ARGUMENTCONCLUSION]

Amy: I disagree; I think all objects in the same room are the same temperature [ARGUMENT-COUNTER]. Conductivity only determines how quickly an object will reach room temperature [ARGUMENT-REASON].

Fran: No, good conductors let in more heat energy than poor conductors, so objects that let in more heat will get hotter [ARGUMENT-CONCLUSION]. For example, when I put a piece of metal and a piece of plastic in hot water the metal was a higher temperature after 30 seconds [ARGUMENT-REASON].

Amy: I guess you're right. Maybe objects are different temperatures [RESPONSIVE].

\section{Baker, Andriessen, Lund, van Amelsvoort, and Quignard (Submitted)}

Baker, Andriessen, Lund, van Amelsvoort, and Quignard (submitted; Baker, Andriessen, Quignard, van Amelsvoort, Lund, Salminen, Litosseliti, \& Munneke, 2002) outline a coherent framework (Rainbow) for analyzing computer-mediated pedagogical debates. Rainbow comprises seven principal analytic categories. The primary focus is on the epistemic nature of the contributions that students make during collaboration. The framework was developed to allow the researchers to investigate what it means for participants to achieve conceptually deeper levels of interaction.

At the most basic level, the Rainbow framework distinguishes between activity that is part of the prescribed assignment and activity that is not (outside-activity includes any interaction that is not concerned with carrying out the researcher-defined task). From there, Rainbow differentiates activity that is part of the prescribed assignment as either task-focused or non task-focused. Non task-focused activity is categorized as either social relation (interaction that is concerned with managing students' social relations with respect to the task) or interaction management (interaction concerned with managing the interaction itself). Task-focused activity is categorized as task management (management of the progression of the task itself), opinions (interaction concerned with expressing opinions with regard to the topic under debate), argumentation (expression of arguments and counterarguments directly related to a thesis), and explore and deepen (interaction concerned with arguments and counterarguments linked together, their relations, and the meaning of the arguments themselves including elaboration, definition, and extension). Baker and colleagues ground the rationale for each of these seven categories carefully in the research on collaborative learning, task-oriented dialogues, verbal interactions, and argumentation theory.

The default level of analysis is the individual student comment because that process allows students' activity to self-define the unit boundaries. Each student comment is then assigned to the category best representing its primary nature. Baker and colleagues also outline the potential for subsequent analysis at micro and macro levels. Researchers may apply the seven codes at a 
smaller grainsize by parsing individual comments into components or apply the codes at a macro level to larger episodes comprising strings of multiple comments focusing on a coherent goal. Finally, while the authors developed Rainbow primarily for use with a text chat system, the authors also outline possible extensions to topical analyses, graphically-mediated debates, and other types of problem-solving.

Table 9. Application of Baker, Andriessen, Lund, van Amelsvoort, and Quignard (submitted) Rainbow framework to argumentation example

$\begin{array}{ll}\text { Comment } & \text { Rainbow } \\ \text { Category }\end{array}$

Fran: I think objects in the same room remain different temperatures because some objects are good conductors and some are bad (Opinion). This determines how much heat energy is allowed in and Opinion out of the object (Argumentation).

Amy: I disagree; I think all objects in the same room are the same temperature (Opinion). Conductivity only determines how quickly anArgumentation object will reach room temperature (Explore and Deepen).

Fran: No, good conductors let in more heat energy than poor conductors, so objects that let in more heat will get hotter (Explore and Deepen). For example, when I put a piece of metal and a piece of plastic in hot Explore and water the metal was a higher temperature after 30 seconds (Argumentation).

Amy: I guess you're right. Maybe objects are different temperatures (Opinion).

Opinion

From the perspective of the Rainbow framework, our student example represents quality argumentation because the example involves conceptual deepening and exploration of the topic (Table 9). Our example in Table 9 is coded at the standard comment level as well as the micro level. The Rainbow framework might analyze the first three comments as a single macro episode representing "explore and deepen."

\section{Nature and Function of Contributions: Affordances, Constraints, and other Considerations}

Frameworks with a focus on the nature and function of contributions within the dialog focus by definition on ongoing discourse. They are therefore best suited for coding synchronous forums or asynchronous forums rather than environments focusing on the juxtaposition of a small number of crafted responses or the interpretation of dialogic artifacts. That said, however, frameworks such as Rainbow can be adapted to other formats as discussed by Baker and colleagues. Of the three frameworks discussed, de Vries, Lund, and Baker's (2002) framework is noteworthy for its detailed consideration of the types of discourse moves that students may make, the Rainbow 
framework is carefully grounded theoretically and is parsimonious enough to simplify application and analysis, and Janssen, Erkens, Jaspers, and Kanselaar's framework offers fantastic potential in terms of its automated capabilities. In sum, these frameworks provide solid and flexible approaches for researchers interested in assessing the nature of student's contributions and the overall effectiveness of online environments designed to encourage substantive discussions about the knowledge and concepts underlying problem solving.

\section{Epistemic Nature of Reasoning}

A fourth focal category of analytic methods revolves around the epistemic nature of students' reasoning. In other words, what types of reasoning are students employing to support their claims or to challenge the claims of others? Both Jimenez-Aleixandre, Rodriguez, \& Duschl (2000) and Duschl (in press) have developed analytic methods designed to address this question using Walton's (1996) argumentation schemes for presumptive reasoning as a theoretical framework. Walton (1996) suggests that dialectical argumentation is grounded in burden of proof, presumption, and plausibility rather than in structural form alone. Walton details twenty-five different argumentation schemes that focus on how presumptions are brought forward in arguments as kinds of premises or as kinds of inferences that link premises to conclusions in a context of argumentative dialog (e.g., argument from evidence to hypothesis or argument from analogy). The function of these schemes involves shifting the weight of presumption from one side of a dialog to the other. An opposing voice can then respond with questions or statements that shift the weight of presumption back upon the original participant. Analysis with this type of framework focuses on categorizing the types of reasoning employed within an argument.

\section{Jimenez-Aleixandre, Rodriguez, \& Duschl: Adding Focus on the Nature of Students' Reasoning}

Jimenez-Aleixandre, Rodriguez, \& Duschl's (2000) framework expands the core Toulmin structural focus with examination of the reasoning functions and strategies used by students. To accomplish this task, Jimenez-Aleixandre, Rodriguez, and Duschl apply a standard Toulmin model to identify how students make use of data, claims, warrants, backings, and qualifiers to support their arguments during small group and whole class discussions. Once these elements are identified, they examine how students elaborate, reinforce, or oppose the arguments of each other by classifying claims and warrants using epistemic operations based on Walton's categories of presumptive reasoning. These epistemic operations include: Induction (looking for patterns or regularities), Deduction (identifying various instances of rules and laws), Causality (relation cause-effect, looking for mechanisms or predictions), Definition (stating the meaning of a concept), Classification (grouping objects or organisms according to criteria), Appeals to Analogy, Exemplar, Instance, Attribute, or Authority (appealing to analogies, instances, or attributes as a means of explanation), Consistency with Other Knowledge, Experience, Commitment to Consistency, or Metaphysical (factors of consistency, particular with experience, or general in need for similar explanations), and Plausibility (predication or evaluation of own or others' knowledge). Finally, they assign a code for activities that appear driven by the requirements of school culture rather than science inquiry. Analysis then compares the proportions of argumentation and epistemic moves made in the dialog. When Jimenez-Aleixandre, Rodriguez, \& Duschl's (2000) framework is applied to the our student example (Table 10), we see the expansion of the core Toulmin approach through the 
categorization of the epistemic nature of each contribution. In assessing the overall quality of our student example, we see that (1) the discourse is content-related rather than task-related, (2) the students justify their ideas, and (3) their reasons focus on causality, consistency, and appeals to instances rather than plausibility or appeals to authority. From the perspective of this framework, therefore, our student example again represents fairly high quality argumentation. This type of framework is particularly well suited for examining the nature of argumentation in environments with ongoing dialog and with pedagogical goals focusing on students learning how to argue within a particular domain.

Table 10: Application of Jimenez-Aleixandre, Rodriguez, \& Duschl's (2000) framework to example argumentation

\section{Comment and Argument Structure Code $\quad$ Epistemic \\ Operation}

Fran: I think objects in the same room remain different

Definition temperatures because some objects are good conductors and some are bad. This determines how much heat energy is allowed in and out of the object [CLAIM].

Amy: I disagree; I think all objects in the same room are the same temperature [COUNTER-CLAIM].

Conductivity only determines how quickly an object will reach room temperature [WARRANT].

Fran: No, good conductors let in more heat energy than poor conductors, so objects that let in more heat will get hotter [REBUTTAL].

For example, when I put a piece of metal and a piece of plastic in hot water the metal was a higher temperature after 30 seconds [DATA].

Definition

Consistency with other Knowledge

Causality

Appeal to an

instance

Amy: I guess you're right. Maybe objects are different

Plausibility temperatures.

\section{Duschl (in press): Synthesizing Walton to Facilitate Application}

Duschl's (in press) framework represents an innovative application of Walton's (1996) framework to scientific argumentation in the classroom. Duschl and colleagues first narrowed Walton's twenty-five categories down to the nine categories that they found to have strong relevance to scientific argumentation in the classroom. These nine categories are represented in Table 11. Distinguishing between even these nine categories, however, proves difficult in coding students' work. Duschl and his group therefore collapsed the nine categories into four categories including requests for information, expert opinion, inference, and analogy. They then apply these 
coding categories at the level of the reasoning sequence, which is approximately at the level of each of the students' comments in our example. Analysis focuses on the number and proportion of each of these epistemic discourse types in students' discussions.

Table 11. Duschl's (in press) framework collapses nine of Walton's (1996) categories into four categories for greater coding reliability

\begin{tabular}{|c|c|c|}
\hline Argument From & Definition & Look for... \\
\hline \multicolumn{3}{|l|}{$\begin{array}{l}\text { Request for } \\
\text { Information }\end{array}$} \\
\hline Sign* & $\begin{array}{l}\text { Reference to spoken/written claims are } \\
\text { used to infer the existence of a property or } \\
\text { event. }\end{array}$ & $\begin{array}{l}\text { References to the } \\
\text { project. "it shows" }\end{array}$ \\
\hline Commitment* & $\begin{array}{l}\text { A claims that } B \text { is, or should be, committed } \\
\text { to some particular position and then claims } \\
\text { that } B \text { should also be committed to an } \\
\text { action based on that position. }\end{array}$ & $\begin{array}{l}\text { Look for a request } \\
\text { for action. } \\
\text { "should..." } \\
\text { "could..." }\end{array}$ \\
\hline $\begin{array}{l}\text { Position to } \\
\text { Know* }\end{array}$ & $\begin{array}{l}\text { Involves request for information. A has } \\
\text { reason to presume that } B \text { has access to } \\
\text { information that } A \text { does not have. }\end{array}$ & $\begin{array}{l}\text { Look for opposition } \\
\text { statement. }\end{array}$ \\
\hline Expert Opinion* & $\begin{array}{l}\text { Reference to an expert source (person, text, } \\
\text { group consensus, etc.) external to the given } \\
\text { information. }\end{array}$ & $\begin{array}{l}\text { "we did this } \\
\text { before" } \\
\text { "the book says" }\end{array}$ \\
\hline \multicolumn{3}{|l|}{ Inference } \\
\hline $\begin{array}{l}\text { Evidence to } \\
\text { Hypothesis* }\end{array}$ & $\begin{array}{l}\text { Reference to premises followed by } \\
\text { conclusion. Includes a hypothesis - a } \\
\text { conjecture or generalizable prediction } \\
\text { capable of being tested. (The hypothesis } \\
\text { can come as part of the "if" or the "then" } \\
\text { part of the argument.) }\end{array}$ & $\begin{array}{l}\text { "I think..." } \\
\text { "it looks like..." "it } \\
\text { probably would..." } \\
\text { "if it had..."" }\end{array}$ \\
\hline $\begin{array}{l}\text { Correlation to } \\
\text { Cause* }\end{array}$ & $\begin{array}{l}\text { Infer a causal connection between two } \\
\text { events. Characterized by an inferential } \\
\text { leap, based on a natural law, but devoid of } \\
\text { any reference to observational evidence. }\end{array}$ & $\begin{array}{l}\text { (Often based on } \\
\text { plausibility rather } \\
\text { than probability.) }\end{array}$ \\
\hline Cause to Effect* & $\begin{array}{l}\text { Reference to premises that are causally } \\
\text { linked to a non-controversial effect. Effect } \\
\text { is an observable outcome, with no need for }\end{array}$ & “it will..." \\
\hline
\end{tabular}




$\begin{array}{lll}\text { testing } & \begin{array}{l}\text { Practical reasoning in which a policy or } \\ \text { Consequences* } \\ \text { action is supported/rejected on the grounds } \\ \text { that the consequences will be good/bad. A } \\ \text { statement about the value of the conclusion } \\ \text { without any expressed concerns for the } \\ \text { properties nor the events that comprise the } \\ \text { full argument. } \\ \text { Argues from one case that is said to be } \\ \text { similar to another. }\end{array} & \begin{array}{l}\text { "then it would be } \\ \text { better" }\end{array} \\ \text { "iticasically } \\ \text { Analogy* }\end{array}$

* Walton's (1996) original categories

In terms of our student example, inference from evidence to hypothesis and inference from cause to effect are considered desirable epistemic moves in scientific argumentation (in comparison to relying on expert options from the textbook or teacher, for example). Our student example (see Table 12) therefore represents high quality argumentation from the perspective of this framework. In this type of argumentative context, the reasoning students use is not based solely on knowledge and probability. Instead, students often focus on shifting presumption onto the other dialogue participants. This scenario of reasoning from a partial set of experiences and evidence accurately represents the dialog in many online environments designed to promote argumentation.

Table 12. Application of Duschl's (in press) framework to argumentation example
Comment
Reasoning

Fran: I think objects in the same room remain different temperatures because some objects are good conductors and some are bad. This determines how much heat energy is allowed in and out of the object.

Amy: I disagree; I think all objects in the same room are the same temperature. Conductivity only determines how quickly an object will reach room temperature.

Inference

(cause to effect)

Fran: No, good conductors let in more heat energy than poor

Inference conductors, so objects that let in more heat will get hotter.

For example, when I put a piece of metal and a piece of plastic in hot water the metal was a higher temperature after (evidence to 30 seconds.

hypothesis)

Amy: I guess you're right. Maybe objects are different temperatures. 


\section{Epistemic Nature of Reasoning: Affordances, Constraints, and other Considerations}

Frameworks that focus on the epistemic nature of reasoning are designed to provide valuable information about how students determine 'what counts' as warranted knowledge and how students determine which ideas should be accepted, rejected, or modified. Rather than assessing normative quality of students' reasoning and contributions, this focal category revolves around the types of reasoning that students use when they propose, support, evaluate, and challenge ideas. There is potential overlap, however, because researchers generally consider certain types of reasoning to be more desirable or normative depending on their theoretical commitments with regard to the nature of argumentation, domain of topic, and pedagogical goals. One advantage of this categorical focus, however, involves the relative content independence afforded in comparison to frameworks focusing specifically on normative quality. Frameworks focusing on the epistemic nature of reasoning therefore require little modification when applying them across related topic areas.

In terms of specific affordances and constraints, Jimenez-Aleixandre, Rodriguez, \& Duschl's (2000) framework is valuable because it integrates an assessment of reasoning type with structural quality. In practice, differentiating between students' epistemic operations can prove difficult using this framework, but this framework's consideration of the nature of students' reasoning and argumentation structure may prove particularly fruitful for those interested in scaffolding students as they engage in argumentation. Duschl's (in press) framework, in turn, is noteworthy for its distillation and synthesis of Walton's (1996) framework into a manageable discipline-specific coding scheme. While Walton (1996) is very attractive in terms of distinguishing epistemic types of arguments, Duschl's framework makes applying Walton feasible.

Overall, these frameworks (and this categorical focus for analysis) apply well to almost any type of environment structure because they focus on a core attribute of all argumentation. Generally speaking, they focus on frequency counts so they are better suited to environments supporting free flowing dialog, such as asynchronous and synchronous discussions rather than the micro analysis of smaller segments.

\section{Patterns and Trajectories of Participant Interaction}

The fifth major category of analytic focus revolves around patterns of interaction. Whereas the category Nature and Function of Contributions within the Dialog (discussed earlier) focuses on the frequencies of various types of contributions, this category focuses specifically on interaction sequences and patterns. Frameworks by Leitão (2000), Hogan, Nastasi, and Pressley (2000), Baker (2003), and Weinberger and Fischer (2006) provide interesting examples of this category of analytic focus.

\section{Leitão (2000): Argument's Potential for Knowledge Building Cycles}

Leitão (2000) considers a specific sequence of argumentation to be particularly fruitful for knowledge building. Based on Piaget's work (1985) and his idea of socio-cognitive conflict, Leitão (2000) envisions argumentation as a social activity in which students confront each other with opposing views and build knowledge by resolving this conflict in a specific manner. In what 
Leitão calls a knowledge building cycle, students (1) construct an argument, which consists of a position and its justification, (2) construct a counterargument in response to the first argument, and (3) create a reply that captures the participants' immediate and secondary reactions to the counterargument.

Counterarguments may (1) support a different perspective of the debate, (2) challenge the validity of the claim, or (3) question the validity of the warrants of the claim. Similarly, the students' replies in the third phase may take several forms, which indicate the degree to which a counterargument is accepted or dismissed in favor of the initial argument. Replies in this third phase include (1) dismissal of the information conveyed by the counterargument, (2) local agreement with the counterargument that acknowledges parts of the counterargument but preserves the initial argument, (3) integrative replies that indicate the speaker's agreement with parts of the counterargument but modify and qualify the initial argument, and (4) a withdrawal of initial view that entails abandoning the first argument in favor of the counterargument. Through these patterns of argumentation, the initial arguments may be preserved, revised or withdrawn. Leitão (2000) argues that these patterns of argumentation optimally shape the process of social knowledge construction (see Figure 3).

From the perspective of Leitão's (2000) framework, our student example represents a complete knowledge building cycle (see Table 13). The episode begins with Fran contributing her initial argument. Amy then counters by bringing the truth of the claim into question. Fran replies by dismissing Amy's counter argument which enables Fran to preserve her initial viewpoint. In this case, Amy accepts Fran's ideas and withdraws her initial viewpoint. From Leitão's (2000) perspective, both this type of outcome and outcomes that result in a revised argument represent successful outcomes of argumentation.

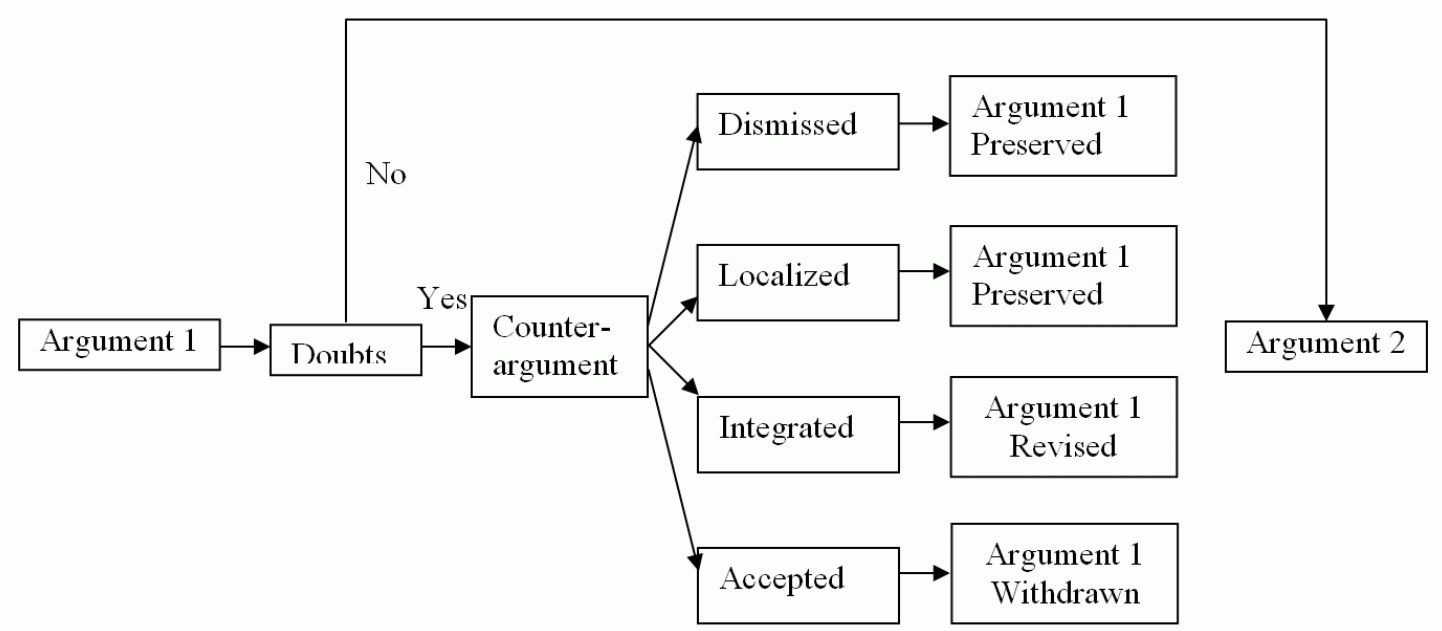

Figure 3: The process of argument reappraisal according to Leitão (2000).

Leitão's type of framework would be well suited for the analysis of an online environment designed to promote knowledge reappraisal. For example, in asynchronous discussion forums or other environments that enable students to construct and revise hypertext through a process of negotiation and collaboration, using this type of framework to examine how students respond to the doubts or counterarguments raised by the other students may prove extremely valuable. 
Table 13. Application of Leitão's (2000) framework to argumentation example

\begin{tabular}{|c|c|c|}
\hline & Comment & Process \\
\hline Fran: & $\begin{array}{l}\text { I think objects in the same room remain different } \\
\text { temperatures because some objects are good conductors } \\
\text { and some are bad. This determines how much heat } \\
\text { energy is allowed in and out of the object. }\end{array}$ & Argument 1 \\
\hline Amy: & $\begin{array}{l}\text { I disagree; I think all objects in the same room are the } \\
\text { same temperature. Conductivity only determines how } \\
\text { quickly an object will reach room temperature. }\end{array}$ & $\begin{array}{l}\text { Counter - bringing the } \\
\text { truth of a claim into } \\
\text { question }\end{array}$ \\
\hline \multirow[t]{2}{*}{ Fran: } & $\begin{array}{l}\text { No, good conductors let in more heat energy than poor } \\
\text { conductors, so objects that let in more heat will get } \\
\text { hotter. }\end{array}$ & Reply - Dismissal \\
\hline & $\begin{array}{l}\text { For example, when I put a piece of metal and a piece of } \\
\text { plastic in hot water the metal was a higher temperature } \\
\text { after } 30 \text { seconds. }\end{array}$ & \\
\hline Amy: & $\begin{array}{l}\text { I guess you're right. Maybe objects are different } \\
\text { temperatures. }\end{array}$ & $\begin{array}{l}\text { Argument } 1 \text { is } \\
\text { preserved }\end{array}$ \\
\hline
\end{tabular}

\section{Hogan, Nastasi, \& Pressley (2000)}

Hogan, Nastasi, and Pressley's (2000) framework examines discourse components, interaction patterns, and reasoning complexity. The framework focuses on (1) how students work to improve weak or incomplete ideas, (2) the patterns of verbal interactions that take place between individuals in scientific sense-making activities, and (3) the relationships between discourse patterns and the sophistication of scientific reasoning in discussions.

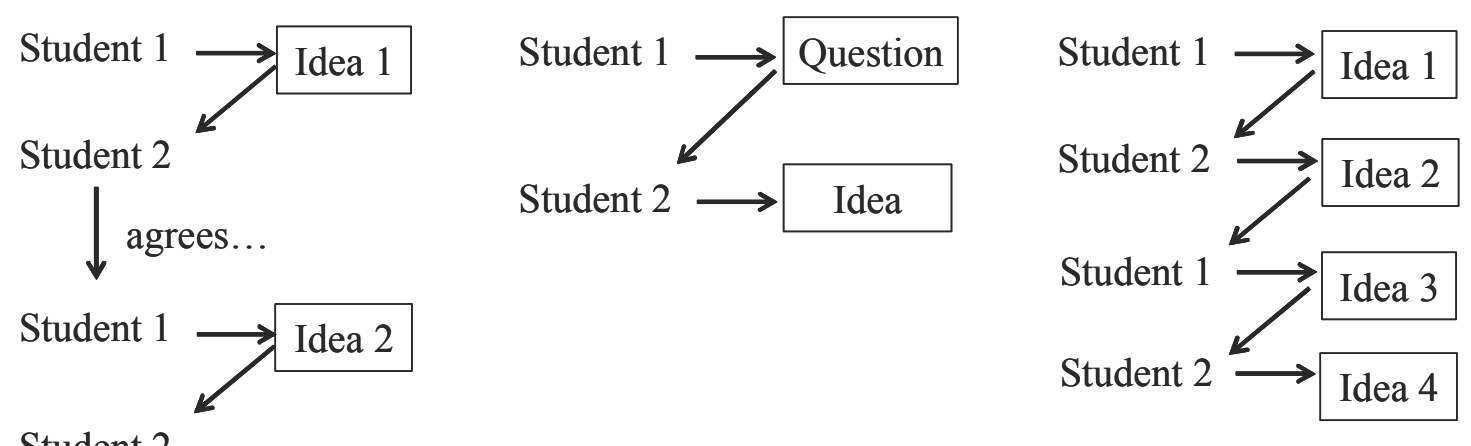

Student 2

Consensual

Responsive

Elaborative

Figure 4: Interaction patterns used by Hogan, Natasi, and Pressley (2000). 
Analysis begins with the assignment of macro-codes to the major modes of a group's discussion at the level of conversational turns. Macro-codes include Knowledge Construction, Logistical, and Off-Task. Micro-codes are then assigned at the level of statement or phrase including Conceptual, Metacognitive, Question-Query, Nonsubstantive, and Other. Micro-codes include multiple subcategories. Researchers then create discourse maps illustrating the patterns of interactions between students based on these codes. Patterns of interaction (Figure 4) include consensual (where a student proposes an idea and another student agrees), responsive (where a student asks a question and another student answers), and elaborative (where students discuss and revise each others ideas). Researchers next assess reasoning complexity (Table 14) and compare this information to the interactional patterns. Note that the reasoning complexity assessment represents an example of the category of analytic focus discussed in the Normative Quality section above.

Table 14. Application of Hogan, Nastasi, and Pressley framework to code reasoning complexity of example argumentation

\begin{tabular}{ll}
\hline Criteria & Operational Definitions (scores for example argument on 0-4 scale) \\
\hline Generativity & $\begin{array}{l}\text { Judged by number of subtopics brought forth within discussion. (4: } \\
\text { Three or more ideas generated) }\end{array}$ \\
Elaboration & $\begin{array}{l}\text { Amount of detail added to subtopics. (0: No elaborations) } \\
\text { Justifications }\end{array}$ \\
$\begin{array}{l}\text { Number of justifications per idea including evidenced-based and } \\
\text { inference-based. (2: Single justifications of more than one idea) }\end{array}$ \\
Explanations & $\begin{array}{l}\text { Number of mechanisms proposed to account for phenomena. (2: } \\
\text { Single mechanism for more than one phenomenon) }\end{array}$ \\
Logical Coherence & $\begin{array}{l}\text { Logical coherence of justifications or explanations for phenomena. } \\
\text { (3: Clear and reasonable connections but lack support) }\end{array}$ \\
Synthesis & $\begin{array}{l}\text { Measure of how opposite views are accounted for. (3: One counter } \\
\text { idea prevails through support given for it) }\end{array}$
\end{tabular}

Our student example represents what Hogan, Nastasi, and Pressley describe as an elaborative interaction pattern. Hogan, Nastasi, and Pressley suggest that elaborative interaction supports quality argumentation because it prolongs discussions and leads to higher levels of reasoning. As presented in Table 14, our student example involves complex reasoning in terms of generativity, logical coherence, and synthesis. Although there is no elaboration present, the student example represents desirable argumentation overall from the perspective of this framework.

\section{Baker (2003)}

Baker's (2003) framework examines the standpoints adopted by individuals during argumentation, how ideas change over time, and the pragmatic function of language. The 
framework focuses on argumentation as a way to facilitate collaborative learning. According to the framework, argumentation transforms the epistemic status of solutions by establishing relations between the proposed solutions and other knowledge or by promoting the negotiation of new meaning (Figure 5). Arguments strengthen the epistemic status of a solution. Counterarguments weaken the epistemic status of a solution. As a discursive activity, argumentation establishes relations between possible solutions and other sources of knowledge. As a dialogic activity, argumentation incorporates aspects of formal and pragmatic dialectics. Through the analyses, this framework measures the strengthening and weakening of the epistemic status of various claims as well as the progression of dialectic moves.

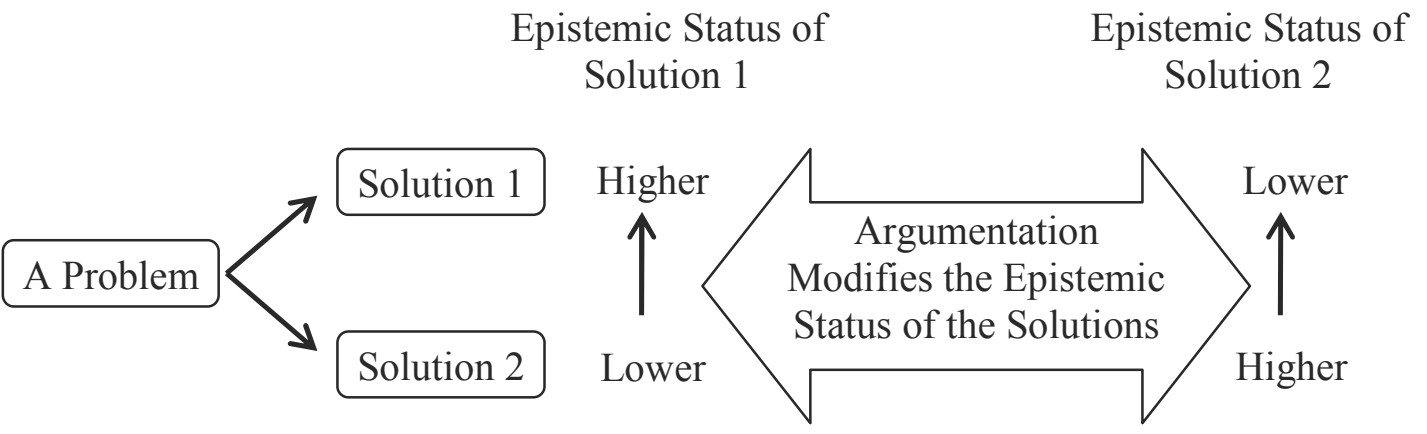

Figure 4. Baker's (2003) framework views argumentation as modifying the epistemic status of the proposed solutions

Table 15 applies Baker's (2003) framework to our student example. Although brief, the discourse changes the epistemic status of Idea A (objects remain different temperatures) and Idea $\mathrm{C}$ (objects become the same temperature). The example therefore represents fairly high quality argumentation from the perspective of this framework. This type of analysis provides a method for tracking the number and types of ideas that students propose and challenge when engaging in argumentation. This method also enables researchers to examine how students use language to generate or validate knowledge.

Table 15. Application of Baker's (2003) framework to example argumentation

\begin{tabular}{llll}
\hline Comment & Fran & Amy & Pragmatic Function \\
\hline 1 & A, B & & Introduces the thesis to be defended. \\
2 & & Counter A & Attack on A weakening A. \\
& & C, D & Introduces alternative ideas C and D \\
3 & Counter D & & Attack on D weakening D. \\
4 & & A & Indicates concession. Strengthening A. \\
\hline
\end{tabular}


Key

A: Objects in the same room remain different temperatures

B: Conductivity determines how much heat energy is allowed in and out of the object

$\mathrm{C}$ : Objects in the same room are the same temperature.

D: Conductivity determines how quickly an object will reach room temperature

\section{Weinberger \& Fischer (2006): A Multi-Dimensional Approach to Analyze Argumentative Knowledge Construction}

Weinberger and Fischer's (2006) framework examines the process through which knowledge is constructed as students engage in argumentation in online environments. Their framework assesses argumentation along four independent dimensions. The participation dimension analyzes the amount of participation by each student and the heterogeneity of participation within the learning group. The framework assesses students through total time in the system as well as through the number of words and messages produced.

The epistemic dimension identifies the theoretical concepts that students use in their argumentation and how they use them in terms of the environment's learning goals. The epistemic dimension is therefore content and environment specific. The epistemic dimension first differentiates between on-task and off-task behavior and then distinguishes between specific epistemic activities. The epistemic dimension thus represents the Nature and Function of Contributions Within the Dialog category discussed earlier.

On the formal argumentative dimension, Weinberger and Fischer (2006) analyze the construction of single arguments through a simplified version of Toulmin's scheme (1958) as well as through the argumentation sequences outlined in Leitão's (2000) work. With respect to the construction of single arguments, simple, qualified, grounded, and qualified and grounded claims are differentiated from non-argumentative discourse moves, such as questions or meta-statements on argumentation. With respect to argumentation sequences, arguments, counterarguments, and (integrative) replies are identified and differentiated from non-argumentative moves. This dimension therefore integrates analysis of interaction and formal structure through a marriage of Toulmin and Leitão.

On the dimension of social modes of co-construction, Weinberger and Fischer (2006) analyze how students refer to the arguments of their learning partners in relation to knowledge acquisition (Teasley, 1997). Different social modes (or interactions) reflect the various ways through which students operate on the reasoning of their learning partners (Teasley, 1997). Students can establish consensus by agreeing with the ideas proposed by their peers, integrating peers' arguments into their own line of argumentation, or by engaging in a conflict-oriented negotiation of different perspectives.

Weinberger and Fischer's (2006) framework is used to analyze our student example along these four dimensions in Table 16. With respect to the participation dimension, Amy (34 words) utters less than half the words Fran (81 words) does. With respect to the epistemic dimension, both Fran and Amy engage in on-task talk and construct relations between the target conceptual space (rather than prior knowledge) and the problem space. Fran, however, constructs inadequate relations, whereas Amy applies the theoretical concepts adequately. On the formal argumentative dimension, Amy and Fran build relatively complete arguments and argumentation sequences (see Toulmin and Leitão). Finally, on the social modes of co-construction dimension, Amy and Fran 
clearly engage in conflict-oriented consensus building as they refer to each other's contributions and attempt to negotiate meaning.

Table 16. Application of Weinberger and Fischer's (2006) framework to argumentation example

Comment

Fran: I think objects in the same room remain different temperatures because some objects are good conductors and some are bad. This determines how much heat energy is allowed in and out of the object.

[Inadequate concept-case-relation / Grounded claim - Argument / Externalization]

Amy: I disagree; I think all objects in the same room are the same temperature.

Conductivity only determines how quickly an object will reach room temperature.

[Adequate concept-case relation / Grounded claim - Counter-argument / Conflictoriented consensus building]

Fran: No, good conductors let in more heat energy than poor conductors, so objects that let in more heat will get hotter. For example, when I put a piece of metal and a piece of plastic in hot water the metal was a higher temperature after 30 seconds.

[Inadequate concept-case-relation / Grounded claim - Counter-argument / Conflictoriented consensus building]

Amy: I guess you're right. Maybe objects are different temperatures.

[Inadequate concept-case-relation / Qualified claim - Integrative reply / Integrationoriented consensus building]

\section{Patterns and Trajectories of Participant Interaction: Affordances, Constraints, and other Considerations}

This analytic category increases the unit of analysis from an individual comment or fragment to an entire knowledge building cycle. As such it allows us to focus on the actual processes of coconstruction of knowledge rather than focusing on frequency counts of elements that correlate to desirable interaction. Leitão (2000), for example, emphasizes the social nature of knowledge building as opposed to online contexts in which students hardly interact with the activities of their learning partners (e.g., by composing elaborate, essay-like replies in discussion boards). This approach thus emphasizes the coherence of argumentative talk between students. This approach also provides a powerful structure within which to relate and examine the other analytic categories (e.g., Hogan, Nastasi, and Pressley's, 2000; Weinberger and Fisher, 2006) One interesting dichotomy involves the presence or absence of a pedagogical goal state within the framework to inform the development of practice. In other words, does the framework provide a road map for instruction in terms of desirable student practice? For example, Baker's (2003) analytic framework provides ways to track the evolution and change in status of the ideas 
discussed by students and how (or if) they are challenged, but the framework provides us less concrete guidance for instruction - What do we want students to know or to be able to do? Other frameworks are more prescriptive in this regard, which may or may not be desirable depending on the goals of the researchers.

This type of analytic focus may be applied across almost all online argumentation environments independent of environment structure or the nature of the artifacts created because this analysis can focus at microgenetic scales as well as broad scales. Increased complexity of application accompanies this increased power, however. The challenge of this analytic category manifests itself in terms of increased amount and complexity of work required to reliably apply these types of analyses across larger samples.

\section{Synthesis}

In this manuscript we have considered several frameworks for analyzing dialogic argumentation in online learning environments. We now return to our original question: Does the dialog from our student example represent quality argumentation? Clearly, it depends on your perspective. Most of the frameworks discussed here would assess the student example as representing fairly desirable argumentative discourse, but often for very different reasons (see Table 17). Clearly the analytic frameworks vary significantly in terms of their focus. Each framework offers various affordances. Researchers exhibit high interest in a host of issues including argument structure, epistemic types of reasoning, conceptual quality and normativity, quality and quantity of warrants, logical coherence of claims and warrants, patterns of participation and interaction, conceptual evolution, and the process of consensus building.

Table 17. Assessment of the Student Example by the frameworks in each category.

Framework

Assessment of Student Example

good fair poor

\section{Formal Argumentation Structure}

Toulmin (1958): Presence of Structural Features

$\mathbf{X}$

Erduran, Osborne, and Simon (2004): Structural Quality of $\quad X$ Oppositional Episodes

\section{Normative Quality}

Clark \& Sampson (2005): Types of Challenges, Types of

Justification, and Conceptual Quality

Kuhn \& Udell (2003): Argumentation Quality and

Epistemic Type of Contributions

Nature and Function of Contributions Within the Dialog

deVries, Lund, \& Baker (2002): Occurrence of Epistemic $\quad X$ Dialogue 
Janssen, Erkens, Jaspers, \& Kanselaar (2006) Automated $\quad$ X

Scoring of Students' Contributions

Baker, Andriessen, Lund, van Amelsvoort, and Quignard $\quad$ X

(submitted): Epistemic Types of Contributions with Focus

on Conceptual Deepening

Epistemic Nature of Reasoning

Jimenez-Aleixandre, Rodriguez, \& Duschl (2000): Structure $\quad X$

and Types of Reasoning

Duschl (in press): Application of Walton to Dialogic $\quad \mathrm{X}$

Argumentation

Patterns and Trajectories of Participant Interaction

\begin{tabular}{ll} 
Leitão (2000): Interaction Sequences for Knowledge & X \\
Building & \\
$\begin{array}{l}\text { Hogan, Nastasi, and Pressley (2000): Interactional } \\
\text { Patterns/Reasoning Complexity }\end{array}$ & X \\
$\begin{array}{l}\text { Baker (2003): How ideas change, pragmatic function of } \\
\text { language }\end{array}$ & X \\
$\begin{array}{l}\text { Weinberger \& Fischer (2006): Social co-construction of } \\
\text { knowledge through argumentation }\end{array}$ & X \\
\hline
\end{tabular}

The first obvious conclusion is that it is insufficient for a researcher to say "we measured the quality of argumentation" or "we successfully supported argumentation." In the former case, the researcher needs to specify the theoretical interpretation of argumentation inherent in the analytic methods. In the latter statement, the reader needs not only to understand the theoretical commitments of the researcher but also the pedagogical goals inherent in the design of the online learning environment. Clearly there are several theoretical perspectives on the nature of argumentation and the aspects of argumentation that should be fostered. In building online environments to support argumentation, researchers need to be clear and specific in terms of their theoretical commitments about argumentation and the pedagogical goals they wish to foster (and concomitantly measure) through the environment. These decisions are foundational in the subsequent adoption or development of an appropriate analytic framework.

Fortunately, researchers have a great deal of flexibility in creating environments to support their theoretical commitments about argumentation and pedagogical goals. Toward this end, as outlined in the introduction, researchers can integrate multiple categories of support functionality into their online learning environments to facilitate argumentation. Similarly, in terms of analysis, broad ranges of approaches have been developed to analyze students' argumentation as presented here through the examples of the various categories of potential analytic focus. Another issue that becomes apparent when reviewing these frameworks involves the potential to synergistically integrate multiple categories of analytic focus within a single framework. By coordinating the analyses of multiple categories simultaneously, we can potentially learn more about students' performance in terms of each individual category. By combining, for example, analysis of formal structure with analysis of the epistemic nature of reasoning, we can build a more accurate discipline-specific understanding of the quality of students' argumentation skills. Integrating other analyses within the analysis of the patterns and trajectories of participant interaction seems the most promising. Most of the other categories of analytic focus correlate 
frequency counts of various components as correlational markers for argumentation quality. Careful tracking of participant interaction and the evolution of ideas would align our analyses more directly, and therefore potentially more validly, with the processes of argumentation we wish to foster. Integrating analyses of other facets of argumentation within the analysis of the patterns and trajectories of interaction therefore proffers a complex but enticing opportunity to view student argumentation through much higher and more authentic resolutions. The challenge, of course, rests in the increased accompanying complexity of conducting such analyses.

Online learning environments offer strong affordances for grappling with these challenges and realizing these gains. Online learning environments incorporate the potential to closely log students' actions and interactions. As we develop technologies to more carefully track and analyze student data, we will have the capability to track interactions and quality more accurately in real time. Based on this information, we could then modify supports for argumentation in real time. Dönmez, Rosé, Stegmann, Weinberger, and Fischer (2005) have made early progress in this regard by harnessing latent text analysis technology to score the quality of students' argumentation products. Similarly, the Multiple Protocol Episode Analysis system (Erkens, 2005; Janssen, Erkens, Jaspers, \& Kanselaar, 2006) can score extended dialogs and messages using a complex rules system instantaneously. In both of these examples, analyses were not conducted in real time, but the potential is staggering.

As we develop more sophisticated methods for analyzing argumentation, we should therefore continue to monitor the possibilities for embedding these analytic methods directly as real time functionality within online learning environments. These analytic models would therefore not only improve our research capabilities but also facilitate higher levels of interactivity and customized scaffolding for students engaging in argumentation in our schools. 


\section{References}

Baker, M. (2003). Computer-mediated argumentative interactions for the co-elaboration of scientific notions. In J. Andriessen, M. Baker \& D. Suthers (Eds.), Arguing to learn: Confronting cognitions in computer-supported collaborative learning environments (pp. 47-78). the Netherlands: Kluwer Academic Publishers

Baker, M., Andriessen, J., Lund, K., van Amelsvoort, M., \& Quignard, M. (submitted). Rainbow: A framework for analysing computer-mediated pedagogical debates. Submitted to International Journal of Computer Supported Collaborative Learning.

Baker, M., Andriessen, J., Quignard, M., van Amelsvoort, M., Lund, K., Salminen, T., Litosseliti, L. \& Munneke, L. (2002). A framework for analysing pedagogically-oriented computer-mediated debates: Rainbow. Cahier de Recherche, Research report IC-3-2002. GRIC-Université Lumière Lyon2, Équipe Interaction \& Cognition.

Bell, P. (1997). Using argument representations to make tkinking visible for individuals and groups. In R. Hall, N. Miyake \& N. Enyedy (Eds.), Proceedings of the Second International Conference on Computer Support for Collaborative Learning (CSCL 1997) (pp. 10-19). Toronto: Toronto University Press.

Bell, P. (2004). Promoting students' argument construction and collaborative debate in the science classroom. In M. C. Linn, E. A. Davis \& P. Bell (Eds.), Internet environments for science education (pp. 115-143). Mahwah, NJ: Erlbaum.

Bell, P., \& Linn, M. C. (2000). Scientific arguments as learning artifacts: Designing for learning from the web with KIE. International Journal of Science Education, 22(8), 797-817.

Bransford, J. D., Brown, A. L., \& Cocking, R. R. (2000). How People Learn: Brain, Mind, Experience, and School. Washington: National Academic Press.

Carter, L. (2003). Argument in hypertext: Writing strategies and the problem of order in a nonsequential world. Computers and Composition, 20, 3-22.

Cavalli-Sforza, V., Lesgold, A., \& Weiner, A. (1992). Strategies for contributing to collaborative arguments. Proceedings of the Fourteenth Annual Conference of the Cognitive Science Soceity, 755-760. Hillsdale, NJ. Lawrence Erlbaum Associates.

Clark, D. B., \& Sampson, V. (2005, June). Analyzing The Quality Of Argumentation Supported By Personally-Seeded Discussions. Paper presented at the annual meeting of the Computer Supported Collaborative Learning (CSCL) Conference, Taipei, Taiwan.

Clark, D. B., \& Sampson, V. (2006, April). Characteristics of Students' Argumentation Practices When Supported by Online Personally-Seeded Discussions. Paper presented at the annual meeting of the National Association of Research in Science Teaching, San Francisco, California.

Clark, D. B., \& Sampson, V. (in press). Personally-seeded discussions to scaffold online argumentation. To appear in International Journal of Science Education.

Cognition and Technology Group at Vanderbilt. (1997). The Jasper Project: Lessons in curriculum, instruction, assessment, and professional development. Mahwah: Erlbaum. 
de Vries, E., Lund, K., \& Baker, M. (2002). Computer-mediated epistemic dialogue: explanation and argumentation as vehicles for understanding scientific notions. The Journal of the Learning Sciences, 11(1), 63-103.

Dillenbourg, P. (2002). Over-scripting CSCL: The risks of blending collaborative learning with instructional design. In P. A. Kirschner (Ed.), Three worlds of CSCL: Can we support CSCL? (pp. 61-91). Heerlen: Open University of the Netherlands.

Dönmez, P., Rosé, C. P., Stegmann, K., Weinberger, A., \& Fischer, F. (2005). Supporting CSCL with automatic corpus analysis technology. In T. Koschmann, D. Suthers \& T. W. Chan (Eds.), Proceedings of the International Conference on Computer Supported Collaborative Learning - CSCL 2005 (pp. 125-134). Taipei, TW: Lawrence Erlbaum.

Duschl, R. (in press). Quality argumentation and epistemic criteria. In S. Erduran and M. Jimenez-Aleixandre (eds.) Argumentation in Science Education: Recent Developments and Future Directions. Springer.

Erduran, S., Simon, S., \& Osborne, J. (2004). TAPping into argumentation: Developments in the application of Toulmin's argument pattern for studying science discourse. Science Education, 88, 915-933.

Erkens, G. (2005). Multiple Episode Protocol Analysis (MEPA). Version 4.10. Utrecht University, The Netherlands.

Erkens, G., \& Janssen, J. (2006). Automatic coding of communication in collaboration protocols. Proceedings of the 7th International Conference of the Learning Sciences (ICLS 2006), Bloomington, IN.

Erkens, G., Kanselaar, G., Prangsma, M., \& Jaspers, J. (2003). Computer Support for Collaborative and Argumentative Writing. In E. De Corte, L. Verschaffel, N. Entwistle, \& J. van Merriënboer (eds) Powerful Learning Environments: Unravelling basic components and dimensions (pp. 157- 176). Amsterdam: Pergamon, Elsevier Science.

Fabos, B., \& Young, M. D. (1999). Telecommunication in the classroom: Rhetoric versus reality. Review of Educational Research, 69(3), 217-259.

Fischer, F. (2001). Gemeinsame Wissenskonstruktion. Analyse und Förderung in computerunterstützten Kooperationsszenarien [Collaborative knowledge construction. Analysis and facilitation in computer-supported collaborative scenarios]. LudwigMaximilians-Universität München, München.

Fischer, F., Bruhn, J., Gräsel, C., \& Mandl, H. (2002). Fostering collaborative knowledge construction with visualization tools. Learning and Instruction, 12, 213-232.

Fischer, F., Kollar, I., Mandl, H., \& Haake, J. (Eds.). (in press). Scripting computer-supported collaborative learning. New York: Springer.

Fisher, C., \& Larkin, J. H. (1986). Diagrams as Working Memory for Scientific Problem Solving (Technical Report). Carnegie-Mellon University Department of Psychology.

Hesse, F. (in press). Being told to do something or just being aware of something? An alternative approach to scripting in CSCL. In F. Fischer, H. Mandl, J. Haake \& I. Kollar (Eds.), Scripting computer-supported communication of knowledge - cognitive, computational and educational perspectives. 
Hogan, K., Nastasi, B., \& Pressley, M. (2000). Discourse patterns and collaborative scientific reasoning in peer and teacher-guided discussions. Cognition and Instruction, 17(4), 379432

Janssen, Erkens, Jaspers, and Kanselaar check for copying and pasting by employing the WCopyFind software.

Janssen, J., Erkens, G., Jaspers, J., \& Broeken, M. (2006, June). Visualization of agreement and discussion processes during online collaborative learning. Paper presented at the 2 nd Special Interest Meeting of EARLI SIGs Instructional Design \& Learning and Instruction with Computers, Leuven, Belgium.

Janssen, J., Erkens, G., Jaspers, J., \& Kanselaar, G. (2006, June/July). Visualizing participation to facilitate argumentation. Proceedings of the 7th International Conference of the Learning Sciences, Bloomington, IN.

Jermann, P., \& Dillenbourg, P. (2003). Elaborating new arguments through a CSCL script. In J. Andriessen, M. Baker \& D. Suthers (Eds.), Arguing to learn: Confronting cognitions in computer-supported collaborative learning environments (pp. 205-226). Dordrecht: Kluwer.

Jermann, P., Soller, A., \& Muehlenbrock, M. (2001). From mirroring to guiding: a review of state of art technology for supporting collaborative learning. Paper presented at the European Computer Supported Collaborative Learning Conference. (EU-CSCL'01), Maastricht, NL.

Jimenez-Aleixandre, M., Rodriguez, M., \& Duschl, R. A. (2000). 'Doing the lesson' or 'doing science': Argument in high school genetics. Science Education, 84(6), 757-792

Joiner, R., \& Jones, S. (2003). The effects of communication medium on argumentation and the development of critical thinking. International Journal of Educational Research, 39(8), 861-971.

Kirschner, P. A., Buckingham Shum, S. J., \& Carr, C. S. (Eds.). (2003). Visualizing argumentation: software tools for collaborative and educational sense-making. London: Springer.

Kollar, I., Fischer, F., \& Hesse, F. W. (in press). Collaboration scripts - a conceptual analysis. Educational Psychology Review.

Kolodner, J. L., Schwarz, B., Barkai, R. D., Levy-Neumand, E., Tcherni, A., \& Turbovsk, A. (1997). Roles of a case library as a collaborative tool for fostering argumentation. In R. Hall, N. Miyake \& N. Enyedy (Eds.), Proceedings of the 1997 computer support for collaborative learning (CSCL 97) (pp. 150-156). Hillsdale, NJ: Erlbaum.

Koschmann, T., Kelson, A. C., Feltovich, P. J., \& Barrows, H. S. (1996). Computer-supported problem-based learning: A principled approach to the use of computers in collaborative learning. In T. Koschmann (Ed.), CSCL: Theory and practice of an emerging paradigm (pp. 83-124). Mahwah, NJ: Erlbaum.

Kuhn, D., Shaw, V., \& Felton, M. (1997). Effects of dyadic interaction on argumentative reasoning. Cognition and Instruction, 15(3), 287-315. 
Leitão, S. (2000). The potential of argument in knowledge building. Human Development, 43, $332-360$.

Linn, M. C., Clark, D., \& Slotta, J. D. (2003). WISE Design for knowledge integration. Science Education, 87(4), 517-538.

Marttunen, M. (1992). Commenting on written arguments as a part of argumentation skills comparison between students engaged in traditional vs on-line study. Scandinavian Journal of Educational Research, 36(4), 289-302.

Marttunen, M. (1997). Teaching argumentation skills in electronic mail environment. Innovations in Education and Training International, 34(3), 208-218.

Marttunen, M., \& Laurinen, L. (2001). Learning of argumentation skills in networked and faceto-face environments. Instructional Science, 29, 127-153.

Oestermeier, U., \& Hesse, F. (2000). Verbal and visual causal arguments. Cognition, 75, 65-104.

Osborne, J., Erduran, S., \& Simon, S. (2004). Enhancing the quality of argumentation in science classrooms. Journal of Research in Science Teaching, 41(10), 994-1020

Pea, R. D. (1994). Seeing what we build together: Distributed multimedia learning environments for transformative communications. Special Issue: Computer support for collaborative learning. Journal of the Learning Sciences, 3(3), 285-299.

Piaget, J. (1985). The equilibrium of cognitive structures: The central problem of intellectual development. Chicago: University of Chicago Press.

Roschelle, J., \& Pea, R. (1999). Trajectories from today's WWW to a powerful educational infrastructure. Educational Researcher, 28(5), 22-25 + 43.

Sampson, V. \& Clark, D. B. (2006, July). Assessment of Argument in Science Education: A Critical Review of the Literature. Paper presented at the International Conference of the Learning Sciences Conference 2006. Bloomington, Indiana.

Scardamalia, M., \& Bereiter, C. (1994). Computer support for knowledge-building communities. Journal of the Learning Sciences, 3(3), 265-283.

Schellens, T., \& Valcke, M. (2006). Fostering knowledge conctruction in university students through asynchronous discussion groups. Computers \& Education, 46(4), 349-370.

Schiffrin, D. (1987). Discourse markers. Cambridge: Cambridge University Press.

Schwarz, B. B. \& Glassner, A. (in press). The role of CSCL argumentative environments for broadening and deepening understanding of the space of debate. In R. Saljo (Ed.), Information Technologies and Transformation of Knowledge.

Schwarz, B. B. (1997). Understanding symbols with intermediate abstractions: An analysis of the collaborative construction of mathematical meaning. In C. Pontecorvo, R. Säljö \& L. B. Resnick (Eds.), Tools, Discourse, and Reasoning. Lucca: NATO series.

Schwarz, B. B., Neuman, Y., Gil, J., \& Ilya, M. (2001). Effects of argumentative activities on collective and individual arguments. In P. Dillenbourg, A. Eurelings \& K. Hakkarainen (Eds.), European perspectives on computer-supported collaborative learning (pp. 545552). Maastricht, NL: University of Maastricht. 
Stegmann, K., Weinberger, A., \& Fischer, F. (2006). Facilitating argumentative knowledge construction with computer-supported collaboration scripts.

Suthers, D. (1998, April). Representations for scaffolding collaborative inquiry on ill-structured problems. Paper presented at the annual conference of the American Educational Research Association, San Diego, CA.

Suthers, D. D., \& Hundhausen, C. D. (2001). Learning by constructing collaborative representations: An empirical comparison of three alternatives. In P. Dillenbourg, A. Eurelings \& K. Hakkarainen (Eds.), European perspectives on computer-supported collaborative learning (pp. 577-592). Maastricht, NL: University of Maastricht.

Suthers, D., \& Weiner, A. (1995). Groupware for developing critical discussion skills. In J. L. Schnase \& E. L. Cunnius (Eds.), CSCL'95, Proceedings of the First International Conference on Computer Support for Collaborative Learning (pp. 341-348). Mahwah, NJ: Lawrence Erlbaum.

Teasley, S. (1997). Talking about reasoning: How important is the peer in peer collaboration? In L. B. Resnick, R. Säljö, C. Pontecorvo \& B. Burge (Eds.), Discourse, tools and reasoning: Essays on situated cognition (pp. 361-384). Berlin: Springer.

Toth, E., Suthers, D., \& Lesgold, A. (2002). "Mapping to know": The effects of representational guidance and reflective assessment on scientific inquiry. Science Education, 86(2), 264286.

Toulmin, S. (1958). The uses of argument. Cambridge: Cambridge University Press.

Veerman, A. L. (2003). Constructive discussions through electronic dialogue. In J. Andriessen, M. Baker \& D. Suthers (Eds.), Arguing to learn: Confronting cognitions in computersupported collaborative learning environments (pp. 117-143). Amsterdam: Kluwer.

Veerman, A. L., \& Treasure-Jones, T. (1999). Software for problem solving through collaborative argumentation. In P. Coirier \& J. E. B. Andriessen (Eds.), Foundations of argumentative text processing (pp. 203-230). Amsterdam: Amsterdam University Press.

Veerman, A. L., Andriessen, J. E. B., \& Kanselaar, G. (1999). Collaborative learning through computer-mediated argumentation. In C. Hoadley \& J. Roschelle (Eds.), Proceedings of the third conference on computer supported collaborative learning (pp. 640-650). Stanford, CA University: Stanford University.

Voss, J. F., \& van Dyke, J. A. (2001). Argumentation in psychology: Background comments. Discourse Processes, 32(2\&3), 89-111.

Walton, D. (1996). Argumentation schemes for presumptive reasoning. Mahwah, NJ: Lawrence Erlbaum Associates

Weinberger, A. (2003). Scripts for Computer-Supported Collaborative Learning. Effects of social and epistemic cooperation scripts on collaborative knowledge construction. Ludwig-Maximilians-University, Munich.

Weinberger, A., \& Fischer, F. (2006). A framework to analyze argumentative knowledge construction in computer-supported collaborative learning. Computers \& Education, 46, $71-95$. 
Weinberger, A., Clark, D., Erkens, G., Sampson, V., Stegmann, K., Janssen, J., et al. (2006). Argumentative Knowledge Construction in CSCL. In S. A. Barab, K. E. Hay \& D. T. Hickey (Eds.), Proceedings of the Seventh International Conference of the Learning Sciences - Making a Difference (pp. 1094-1100). Mahwah, NJ: Erlbaum.

Weinberger, A., Stegmann, K., Fischer, F., \& Mandl, H. (in press). Scripting argumentative knowledge construction in computer-supported learning environments. In F. Fischer, H. Mandl, J. Haake \& I. Kollar (Eds.), Scripting computer-supported communication of knowledge - cognitive, computational and educational perspectives.

Wolfe, C. R. (1995). Homespun hypertext: Student-constructed hypertext as a tool for teaching critical thinking. Special Issue: Psychologists teach critical thinking. Teaching of Psychology, 22(1), 29-33. 